\title{
Interannual to Decadal Variability of Tropical Indian Ocean Sea Surface Temperature: Pacific Influence versus Local Internal Variability 0
}

\author{
Lei Zhang, ${ }^{a}$ Gang Wang, ${ }^{\text {a }}$ Matthew Newman, ${ }^{\text {b,c }}$ And Weiging Han ${ }^{\mathrm{a}}$ \\ ${ }^{a}$ Department of Atmospheric and Oceanic Sciences, University of Colorado Boulder, Boulder, Colorado \\ ${ }^{\mathrm{b}}$ Cooperative Institute for Research in Environmental Sciences, University of Colorado Boulder, Boulder, Colorado \\ ${ }^{\mathrm{c}}$ National Oceanic and Atmospheric Administration, Earth Systems Research Laboratory, Boulder, Colorado
}

(Manuscript received 19 October 2020, in final form 22 December 2020)

\begin{abstract}
The Indian Ocean has received increasing attention for its large impacts on regional and global climate. However, sea surface temperature (SST) variability arising from Indian Ocean internal processes has not been well understood particularly on decadal and longer time scales, and the external influence from the tropical Pacific has not been quantified. This paper analyzes the interannual-to-decadal SST variability in the tropical Indian Ocean in observations and explores the external influence from the Pacific versus internal processes within the Indian Ocean using a linear inverse model (LIM). Coupling between Indian Ocean and tropical Pacific SST anomalies (SSTAs) is assessed both within the LIM dynamical operator and the unpredictable stochastic noise that forces the system. Results show that the observed Indian Ocean basin (IOB)-wide SSTA pattern is largely a response to the Pacific ENSO forcing, although it in turn has a damping effect on ENSO especially on annual and decadal time scales. On the other hand, the Indian Ocean dipole (IOD) is an Indian Ocean internal mode that can actively affect ENSO; ENSO also has a returning effect on the IOD, which is rather weak on decadal time scale. The third mode is partly associated with the subtropical Indian Ocean dipole (SIOD), and it is primarily generated by Indian Ocean internal processes, although a small component of it is coupled with ENSO. Overall, the amplitude of Indian Ocean internally generated SST variability is comparable to that forced by ENSO, and the Indian Ocean tends to actively influence the tropical Pacific. These results suggest that the Indian-Pacific Ocean interaction is a two-way process.
\end{abstract}

KEYWORDS: Indian Ocean; Pacific Ocean; Atmosphere-ocean interaction; ENSO; Climate variability

\section{Introduction}

The Indian Ocean plays an important role in the Earth climate on time scales ranging from intraseasonal to centennial. Recent studies show that the warming trend and decadal variability of Indian Ocean sea surface temperature (SST) can have large impacts on climate both within the Indian Ocean rim regions and in other sectors of the globe via atmospheric teleconnection [see review by Han et al. (2014b)]. However, as the Indian Ocean is strongly affected by El Niño-Southern Oscillation (ENSO), the SST variability generated by processes intrinsic to the Indian Ocean is difficult to quantify, and studies on decadal and longer time scale variability are lacking [e.g., see review by Han et al. (2014b)].

On interannual to decadal time scales, Indian Ocean SST variability is dominated primarily by two patterns: the Indian Ocean basin mode (IOB) and the Indian Ocean dipole (IOD). (Hereafter, decadal variability is used to mean variability on a time scale from one to a few decades.) The IOB, the leading empirical orthogonal function $(\mathrm{EOF})$ of Indian Ocean SST interannual variability, has a basinwide warming/cooling pattern across the tropical Indian Ocean and usually lags ENSO by a few months. Studies have suggested that it is largely driven by ENSO-induced cloud and surface flux variations (e.g., Klein et al. 1999). On decadal time

Supplemental information related to this paper is available at the Journals Online website: https://doi.org/10.1175/JCLI-D-200807.s1.

Corresponding author: Lei Zhang, lezh8230@colorado.edu scales, before about 1985 the IOB and the interdecadal Pacific oscillation (IPO), an ENSO-like pattern of decadal variability (Power et al. 1999), were positively correlated (Dong et al. 2016). Since 1985, however, the correlation has been negative (Han et al. 2014a). Recent analysis of climate model experiments suggests that this reversed relationship resulted from the external forcing of anthropogenic greenhouse gases on multidecadal time scales (Dong and McPhaden 2017; Zhang et al. 2018b) and volcanic eruptions on decadal time scales (Zhang et al. 2018b). However, the detailed features of SST variability internal to the Indian Ocean, including the effects of natural internal climate variability and natural external forcing, remain unclear.

The IOD, the second EOF of Indian Ocean SST interannual variability, has an east-west SST dipole structure accompanied by prominent zonal wind anomalies (Saji et al. 1999; Webster et al. 1999). Empirical studies suggest that while some IOD events co-occur with ENSO, others are independent of ENSO (Allan et al. 2001; Yamagata et al. 2004; Chang et al. 2006; Meyers et al. 2007; Sun et al. 2015). Climate model simulations agree with the observational analyses, showing that in some models the IOD tends to be triggered by ENSO ( $\mathrm{Yu}$ and Lau 2005; Loschnigg et al. 2003; Lau and Nath 2004; Fischer et al. 2005; Saji et al. 2006), whereas in others the IOD can be selfgenerated and the dominant SST pattern is unchanged when the Pacific Ocean is decoupled (Fischer et al. 2005; Yang et al. 2015). On decadal time scales, variations of the IOD index are independent of decadal variability of ENSO (Song et al. 2007; Tozuka et al. 2007), suggesting that decadal variability of the IOD may be intrinsic to the Indian Ocean ocean-atmospheric coupled system. 
In addition to the IOB and IOD, other SST patterns of interannual variability, such as the subtropical Indian Ocean dipole (SIOD; e.g., Behera and Yamagata 2001; Reason 2002; Suzuki et al. 2004), have been identified. The SIOD is located in the extratropical south Indian Ocean and its formation appears related to the surface mixed layer heat anomalies caused by heat flux variations (Hermes and Reason 2005; Huang and Shukla 2007; Morioka et al. 2010, 2013; Kataoka et al. 2012). Using the SIOD index defined by earlier studies (e.g., Behera and Yamagata 2001), the SIOD and ENSO indices have significant correlations (Zinke et al. 2004; Zhang et al. 2019b; Hermes and Reason 2005); using a new SIOD index with the domain defining its east pole shifted southward, however, it is independent of ENSO (Zhang et al. 2019b).

While the atmospheric bridge facilitates the interbasin interaction between the Indian and Pacific Oceans (Alexander et al. 2002; Huang and Kinter 2002; Xie et al. 2002; Izumo et al. 2014; Deepa et al. 2018, 2019; Han et al. 2018; Zhang and Han 2020), the Pacific can also affect the Indian Ocean through an oceanic connection: the Indonesian Throughflow (ITF) (Schott et al. 2009; Schwarzkopf and Böning 2011; Feng et al. 2011; Trenary and Han 2012, 2013; Lee et al. 2015; Nieves et al. 2015; Cheng et al. 2017; Desbruyères et al. 2017; Li et al. 2017, 2018; Zhang et al. 2018a). The ITF transports warmer and fresher waters from the Pacific to the Indian Ocean (Hirst and Godfrey 1993; Gordon and Fine 1996; Meyers 1996; van Sebille et al. 2014; Dong and McPhaden 2016). As a result, the Pacific impact may be communicated to the Indian Ocean in a variety of ways. Yet, the overall impact of ENSO on the Indian Ocean variability is still not completely clear. On the other hand, since most previous studies focus on the relationship between ENSO and individual climate modes in the Indian Ocean, the overall Indian Ocean internal variation and its response to the Pacific variability is still missing and worth deeper investigation.

To quantify the coupled dynamics between the tropical Pacific and Indian Oceans, in this study we determine a linear inverse model (LIM) from the observed evolution of seasonal SST anomalies within each basin. We use the LIM to diagnose the relative importance of Indian Ocean internal dynamics compared to its coupling with the tropical Pacific for interannual-to-decadal SST variability, with a focus on the leading tropical Indian Ocean SST EOF patterns (IOB, IOD, and SIOD). The effect of anthropogenic warming is removed prior to our analysis. The rest of the paper is organized as follows: section 2 briefly introduces the LIM, section 3 presents data and dominant EOF patterns in the tropical Indian Ocean, section 4 explores the leading eigenmodes on the basis of LIM application, section 5 reports the primary results, and finally section 6 provides a summary and discussion.

\section{Linear inverse model}

Here we apply the LIM to a state vector made up of 3-month running-mean tropical Pacific and Indian Ocean SST anomalies (SSTA). The LIM empirically estimates the linear dynamics of a system from its time-lag covariance statistics. It has been widely used in the climate science community, including studying ENSO dynamics and decadal climate prediction
(Penland and Sardeshmukh 1995; Newman et al. 2003; Newman 2007; Newman and Sardeshmukh 2008; Solomon and Newman 2012; Cavanaugh et al. 2014; Newman et al. 2016). A LIM can extract dynamically relevant coupled structures that oscillate at different time scales without time filtering (Penland and Sardeshmukh 1995; Newman 2007), and it can provide insight into coupling between different processes or different domains (Newman 2007; Newman et al. 2011).

The LIM is briefly summarized as follows. Let $\mathbf{x}$ represent seasonal SSTA. In the LIM, the evolution of $\mathbf{x}$ is approximated by the sum of deterministic (predictable) and stochastic (unpredictable) components:

$$
d \mathbf{x} / d t=\mathbf{L x}(t)+\boldsymbol{\xi}(t)
$$

where $\mathbf{L}$ is the dynamical operator that captures deterministic seasonal anomaly evolution and $\boldsymbol{\xi}(t)$ is temporally white noise (which could still have spatial structure). Note that (1) can be a suitable — and, importantly, testable-approximation of a highly nonlinear system whose nonlinear terms decorrelate much more rapidly than its linear terms (Hasselmann 1976; Penland 1996; Just et al. 2001). Physically, this means that in Eq. (1), tropical Pacific-Indian Ocean coupled processes acting on time scales shorter than a season are mostly approximated by white noise $\xi(t)$, except for the portion that may be linearly parameterizable upon $\mathbf{x}$, which is contained within the dynamical operator $\mathbf{L}$.

The forward solution of (1),

$$
\mathbf{x}(t+\tau)=\exp (\mathbf{L} \tau) \mathbf{x}(t)+\boldsymbol{\varepsilon}=\mathbf{G}(\tau) \mathbf{x}(t)+\boldsymbol{\varepsilon},
$$

describes the SSTA evolution, where $\mathbf{G}(\tau)=\exp (\mathbf{L} \tau)$ and $\boldsymbol{\varepsilon}$ is the LIM forecast error. The operator $\mathbf{L}$ can be calculated from observations at some training lag $\tau_{0}$ using the lag-covariance matrices $\mathbf{C}_{\tau}=\left\langle\mathbf{x}(t+\tau) \mathbf{x}(t)^{\mathrm{T}}\right\rangle$ as

$$
\mathbf{L}=\frac{1}{\tau_{0}} \ln \left\{\mathbf{C}_{\tau 0} \mathbf{C}_{0}^{-1}\right\}
$$

A fluctuation-dissipation relationship can also be derived from (1) as

$$
\mathbf{L} \mathbf{C}_{0}+\mathbf{C}_{0} \mathbf{L}^{\mathrm{T}}+\mathbf{Q}=0
$$

where $\mathbf{C}_{0}$ is the zero-lag covariance matrix and $\mathbf{Q}$ is the noise covariance matrix [see Penland and Sardeshmukh (1995) for details]. To use the LIM to diagnose the coupled SSTA dynamics within the tropical Pacific and Indian Ocean basins, we follow the approach of Newman (2007) by employing the state vector

$$
\mathbf{x}=\left[\begin{array}{l}
\mathbf{x}_{P} \\
\mathbf{x}_{I}
\end{array}\right]
$$

where $\mathbf{x}_{p}$ and $\mathbf{x}_{I}$ are the leading PC time series of the SSTA in the tropical Pacific and Indian Ocean, respectively. Now (1) becomes the coupled dynamical system

$$
\frac{d \mathbf{x}}{d t}=\frac{d}{d t}\left[\begin{array}{c}
\mathbf{x}_{P} \\
\mathbf{x}_{I}
\end{array}\right]=\left[\begin{array}{ll}
\mathbf{L}_{P P} & \mathbf{L}_{P I} \\
\mathbf{L}_{I P} & \mathbf{L}_{I I}
\end{array}\right]\left[\begin{array}{c}
\mathbf{x}_{P} \\
\mathbf{x}_{I}
\end{array}\right]+\left[\begin{array}{c}
\boldsymbol{\xi}_{P} \\
\boldsymbol{\xi}_{I}
\end{array}\right],
$$



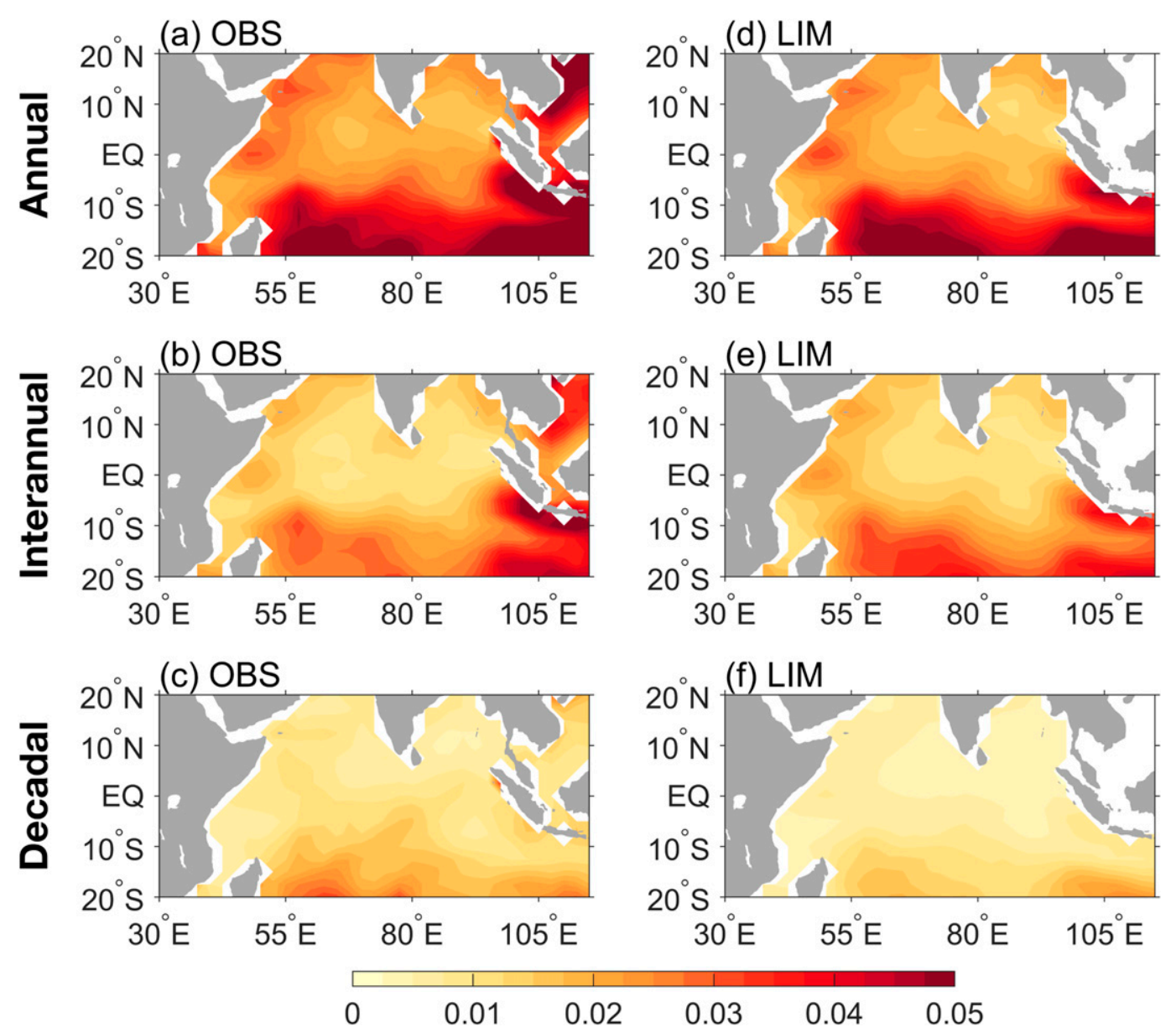

FIG. 1. (a)-(c) Observed and (d)-(f) LIM predicted SSTA variance $\left({ }^{\circ} \mathrm{C}^{2}\right)$ based on monthly SSTA with 1890-2015 climatology removed and 3-month running mean applied. The global mean SSTA-related pattern is also removed prior to our analysis (section 3a). Shown are (top) annual mean SSTA; (middle) interannual SSTA, which is the annual mean SSTA subtracts 5-yr running mean; and (bottom) 5-yr running mean, representing decadal SSTA.

where the dynamical operator $\mathbf{L}$ consists of four parts: the internal dynamics $\mathbf{L}_{P P}$ within the tropical Pacific, the internal dynamics $\mathbf{L}_{I I}$ within the tropical Indian Ocean, and the coupling dynamics between the Pacific and the Indian Ocean represented by $\mathbf{L}_{P I}$ and $\mathbf{L}_{I P}$. The terms $\boldsymbol{\xi}_{P}$ and $\boldsymbol{\xi}_{I}$ are the white noise forcings of $\mathbf{x}_{P}$ and $\mathbf{x}_{I}$, respectively. We can then decouple the dynamics by setting $\mathbf{L}_{P I}=\mathbf{L}_{I P}=0$ (see section 5).

In this study, 20 principal components (PCs) were used for each domain, which explains $96 \%$ of the tropical Pacific and $94 \%$ of the tropical Indian Ocean SSTA variability. A lag of $\tau_{0}=3$ months was used to determine $\mathbf{L}$, which was chosen since we applied a 3-month running mean to the observed SSTA. As mentioned above, this means that in our diagnosis the coupling processes between the two basins are deterministic for time scales longer than three months but are largely represented by noise for shorter time scales. To investigate the LIM predicted SSTA PCs, Eq. (6) is integrated forward for 126000 years (1000 times the observed length), from the first-month values of the observed PCs. This run, as a LIM fully coupled control experiment ("fully coupled"), uses the method in Penland and Matrosova (1994) and Newman (2007) and can be treated as a stochastically forced model simulation. The time step is set to $1 / 120$ month, and random noise is generated based on the eigenanalysis of $\mathbf{Q}$. The LIM runs predict the PC time series corresponding to specific EOF patterns in the observation. Then, the LIM integrated SSTA datasets are obtained by taking the summation over the LIM-predicted PCs after they have been reweighted with their corresponding EOFs.

To evaluate the LIM, we compared its predicted SSTA variance within the interannual and decadal frequency bands to observations, where "decadal" variability is determined from 5-yr running mean data (roughly representing a 10-yr low-pass filter), and "interannual" variability is then the difference between annual mean and 5-yr running mean data (roughly representing a bandpass filter of 2-10 years). Using an 8-yr high-pass and low-pass filter to isolate the interannual and decadal signals yields very similar results to those shown in this study (figure not shown). [A complementary version of this test, in which LIM lag covariance is compared to observations (Penland 1989; Newman and Sardeshmukh 2008), was also performed; see Fig. S1 in the online supplemental material.] Results of this test are shown in Fig. 1. For annual mean SSTA in 

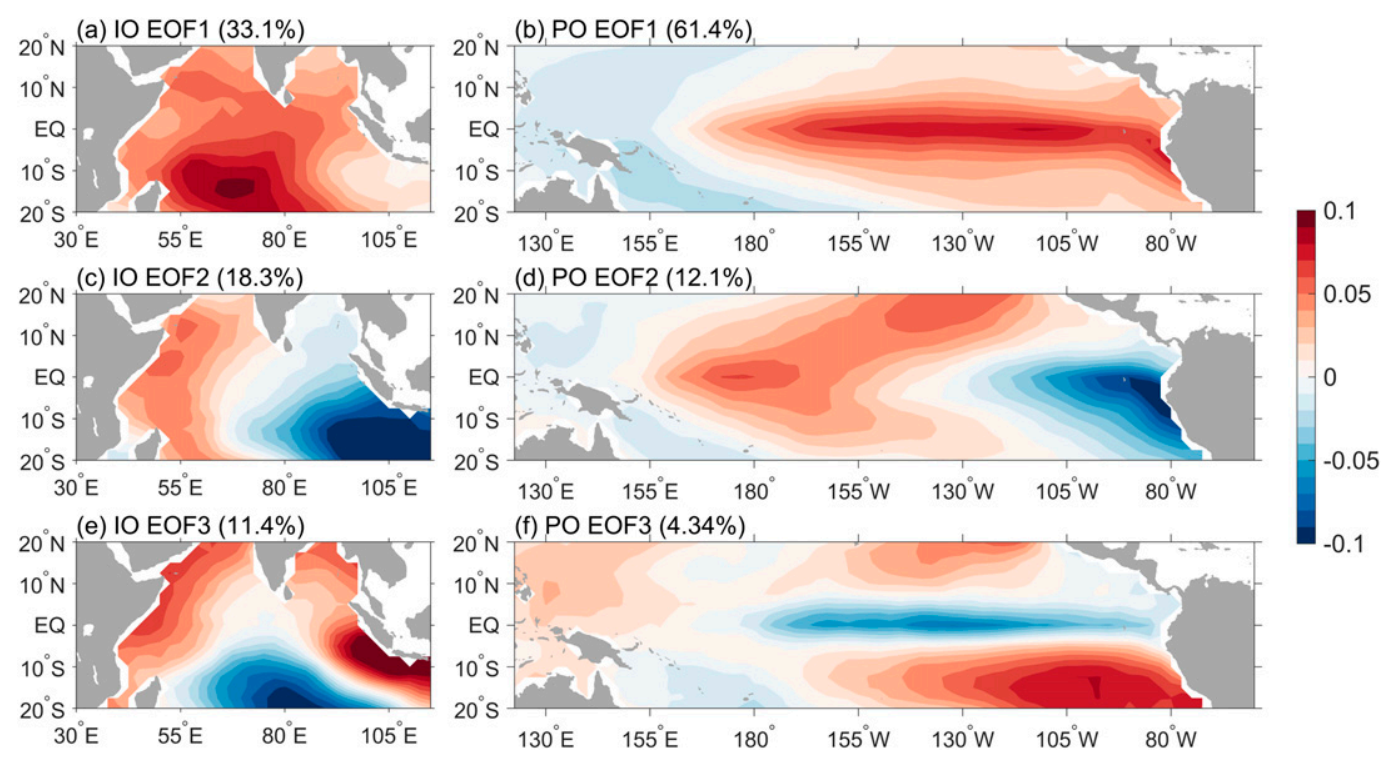

FIG. 2. Leading EOFs of 3-month running mean (left) tropical Indian Ocean SSTA and (right) tropical Pacific SSTA in 1890-2015 after global mean SSTA regression subtracted. Numbers in the parentheses denote fraction of variance explained by each EOF for its respective field.

observations, the maximum variance is located in the south of the tropical Indian Ocean and strongly decreases to the north. For interannual and decadal time scales, the variance maintains this spatial structure although the amplitude becomes much weaker. The LIM generates a quite similar spatial variance pattern relative to observations. Given that the LIM reproduces observed spatiotemporal SSTA covariability statistics, and furthermore its seasonal forecasts have skill comparable to current operational coupled general circulation models (CGCMs) throughout most of the tropical Indo-Pacific [not shown but see Newman and Sardeshmukh (2017)], we use it next to diagnose tropical Indo-Pacific coupling.

\section{Data and dominant SST patterns}

\section{a. Data}

The observed global monthly SST were taken from several datasets including the Hadley Centre Sea Ice and SST dataset version 1.1 (HadISST; $1^{\circ} \times 1^{\circ}$; Rayner et al. 2003), National Oceanic and Atmospheric Administration (NOAA) Cooperative Institute for Research in Environmental Sciences (CIRES) Twentieth Century Reanalysis version $2 \mathrm{c}\left(1.875^{\circ} \times 1.9^{\circ}\right.$; Giese et al. 2016), Centennial in situ Observation-Based Estimates (COBE) SST2 $\left(1^{\circ} \times 1^{\circ}\right.$; Hirahara et al. 2014), European Centre for Medium-Range Weather Forecasts (ECMWF) interim reanalysis (ERA-Interim; $1^{\circ} \times 1^{\circ}$; Dee et al. 2011), ECMWF twentieth century reanalysis $\left(\right.$ ERA-20C; $1^{\circ} \times 1^{\circ}$; Poli et al. 2016), NOAA Extended Reconstructed SST version $3 \mathrm{~b}\left(2^{\circ} \times 2^{\circ}\right.$; Smith et al. 2008) and version $4\left(2^{\circ} \times 2^{\circ}\right.$; Huang et al. 2015; Liu et al. 2015), and Hurrell SST $\left(1^{\circ} \times 1^{\circ}\right.$; Hurrell et al. 2008). To minimize the inconsistency among datasets due to the sparse observations before the 1980 s, we first interpolated the SST data onto a common $2.5^{\circ} \times 2.5^{\circ}$ grid, and then obtained the averaged SST ranging from 1890 to 2015 from different datasets. The monthly climatological mean was removed to obtain the monthly SSTA, which was then smoothed by a 3-month running mean. To remove the global warming-related SSTA pattern prior to our analysis, we regressed the SSTA at each grid point to the global mean SSTA time series, and then subtracted the regressed SSTA at each grid point from the 3-month running mean SSTA data. Similar analyses were also applied to each individual dataset, and there were no essential differences compared to the results from the ensemble mean data. Therefore, we only show our analysis results based on the ensemble mean SST (hereafter denoted as the "observation") in this paper.

\section{b. Leading EOFs}

Figure 2 shows the leading EOF patterns of seasonal mean (i.e., 3-month running mean) SSTA in the tropical Indian and Pacific Oceans $\left(20^{\circ} \mathrm{N}-20^{\circ} \mathrm{S}\right)$, and Fig. 3 has the corresponding PC time series for the tropical Indian Ocean EOFs. A few characteristics can be noted. Clearly, ENSO is the dominant mode in the Pacific, explaining $61 \%$ variance. In the tropical Indian Ocean, the three leading EOFs together explain over $60 \%$ variance of the SST variability. A basinwide warming pattern emerges as the leading mode (EOF1), with maximum anomalies occurring south of the equator. This spatial structure is somewhat different from the IOB pattern with the global mean SST component included (Du et al. 2013), because the maximum warming trend occurs in the equatorial and northern Indian Ocean (e.g., Han et al. 2014a; also see Fig. S2). Its PC is highly correlated with the SSTA averaged over the tropical Indian Ocean (Fig. 3a), with a correlation coefficient of 0.94 (>99\% significance) from 1890 to 2015 . Therefore, EOF1 is referred to as the IOB.

The second EOF in the Indian Ocean is an IOD-like pattern. However, its SSTA maximum in the eastern basin is displaced 
(a) PC1 vs IOB index $(r=0.94)$

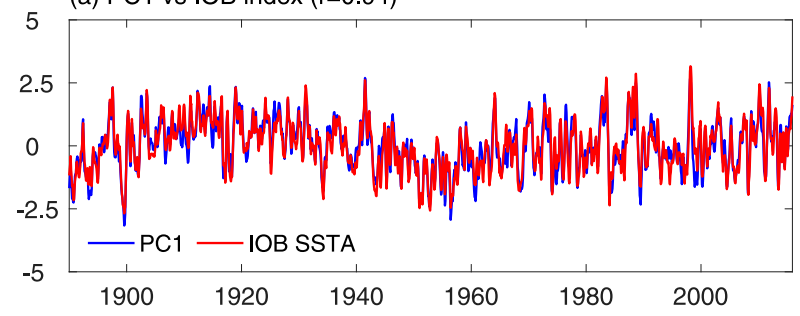

(b) PC2 vs IOD index $(r=0.71)$

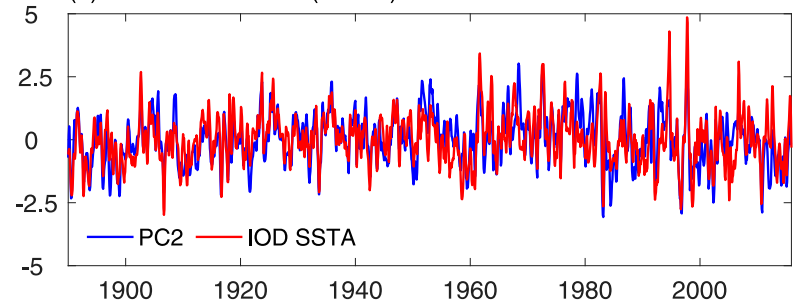

(c) PC3 vs SIOD index $(r=0.42)$

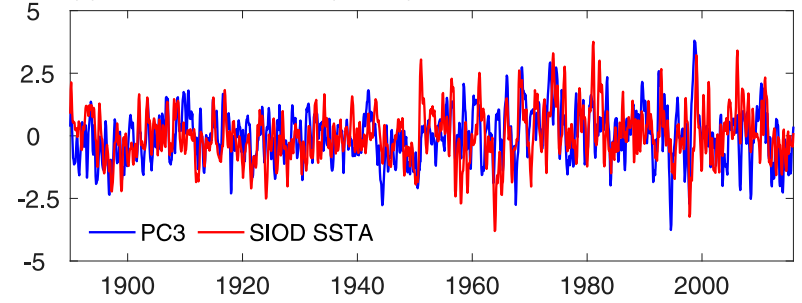

FIG. 3. Comparison of leading principal component (PC) time series of tropical Indian Ocean SSTA (blue curves) in Fig. 2 and climate mode indices (red curves). (a) PC1 time series and averaged tropical Indian Ocean SSTA; (b) PC2 time series and IOD index; (c) PC3 time series and SIOD index. All indices are from the observational data with global mean SSTA regression removed and normalized after 3-month running mean. Numbers in parentheses denote the correlation coefficients between the two indices.

southward from $0^{\circ}-10^{\circ} \mathrm{S}$ to $10^{\circ}-20^{\circ} \mathrm{S}$, differing from the standard IOD definition (Saji et al. 1999). Therefore, EOF2 is referred to as the IOD-like mode. Nevertheless, the PC2 time series and the dipole mode index (DMI), defined as the SSTA difference between $50^{\circ}-70^{\circ} \mathrm{E}, 10^{\circ} \mathrm{S}-10^{\circ} \mathrm{N}$ and $90^{\circ}-110^{\circ} \mathrm{E}, 10^{\circ} \mathrm{S}-$ $0^{\circ}$ (Saji et al. 1999; Saji and Yamagata 2003), are significantly correlated at a value of 0.71 ( $>99 \%$ significance) from 1890 to 2015 (Fig. 3b). Note that the LIM is constructed using PC2, which corresponds to the IOD index very well. Hence, the LIM can faithfully represent the IOD, despite the differences in the EOF2 and the typical IOD pattern.

EOF3 has a more complex SSTA pattern (Fig. 2e), with positive SSTA occurring in the eastern and western basins and negative SSTA occurring in the south Indian Ocean. While the SSTA maximum occurs near the coasts of Sumatra and Java, which resembles the IOD, the opposite signed SSTA in the subtropical basin resembles the SIOD. Overall, the SSTA patterns associated with EOF3 and the SIOD are qualitatively but not quantitatively similar (Fig. S3), and while PC3 is significantly correlated with the SIOD index, defined as the SSTA difference between western $\left(55^{\circ}-65^{\circ} \mathrm{E}, 37^{\circ}-27^{\circ} \mathrm{S}\right)$ and eastern $\left(90^{\circ}-100^{\circ} \mathrm{E}, 28^{\circ}-18^{\circ} \mathrm{S}\right)$ subtropical south Indian Ocean (Behera and Yamagata 2001), this correlation is relatively weak ( $r=$ 0.42 , although this is $99 \%$ significant). These results suggest that EOF3 over the tropical Indian Ocean is partly associated with the SIOD signatures in the tropics, but other factors (e.g., the Asian-Australian monsoon) may also play a role in contributing to this mode.

\section{Dynamical eigenanalysis between Indian Ocean variability and ENSO}

\section{a. Eigenanalysis of LIM}

To better understand the oscillation patterns in the tropical Indian-Pacific coupled system, we performed eigenanalysis of the dynamical operator $\mathbf{L}, \mathbf{L u}_{j}=\mathbf{u}_{j} \lambda_{j}$, where $\mathbf{u}$ are the eigenmodes and $\lambda$ are the corresponding eigenvalues. The eigenvalues may be complex while the conjugated eigenvalues represent propagating eigenmodes in pairs. The term $\mathbf{x}$ can be expressed as a summation over this eigenmode space as

$$
\mathbf{x}=\sum_{j} \mathbf{u}_{j} \alpha_{j}(t)
$$

where $\alpha_{j}(t)$ is the time series of the $j$ th eigenmode projected onto the data (i.e., the $j$ th principal component). The leading eigenmodes of $\mathbf{L}$ are shown in Fig. 4. The eigenmodes are ordered by decreasing decay time scales, or $e$-folding times (EFTs), $1 / \operatorname{Re}\left(\lambda_{j}\right)$. Propagating eigenmodes have complex eigenvalues with period $2 \pi / \operatorname{Im}\left(\lambda_{j}\right)$, while stationary eigenmodes have eigenvalues with zero imaginary part [see Penland (1996) and Newman (2007) for details]. Hence, this analysis can extract the least damped modes and the associated stationary and propagating patterns, which are sometimes called principal oscillation patterns (POPs) (Penland and Sardeshmukh 1995; von Storch et al. 1995). Note that unlike EOFs, the eigenmodes of $\mathbf{L}$ represent the system dynamics and therefore are generally nonorthogonal, since $\mathbf{L}$ is not self-adjoint in most geophysical systems (e.g., Moore and Kleeman 1999). As a consequence, anomaly amplification in Eq. (1) can take place when subsets of the eigenmodes evolve from destructive to constructive interference.

Here we show the five least damped eigenmodes with EFTs ranging from 0.5 to 1 year in Fig. 4 , four of which are associated with propagating patterns with periods from 3 to 35 years. The decadal modes have spatial structures reminiscent of the IPO in the Pacific basin [cf. Fig. 4a herein to Fig. 2a of Han et al. (2014a) and Zhang et al. (1998)], with considerably broader anomalies in both zonal and meridional directions compared to eigenmodes with interannual periods (cf. Figs. 4a and 4e). Even though both the IPO and ENSO correspond to Indian Ocean warming with their maxima occurring east of Madagascar, warming associated with interannual ENSO spreads over the entire basin whereas that associated with IPO extends from the maximum in the central south Indian Ocean to the central and eastern equatorial basin. Eigenmode 2 is another decadal mode, with a period of 18 years and east-west dipole structure over the Pacific Ocean (Fig. 4c). The corresponding structure over the Indian Ocean resembles that of eigenmode 1 . The two 

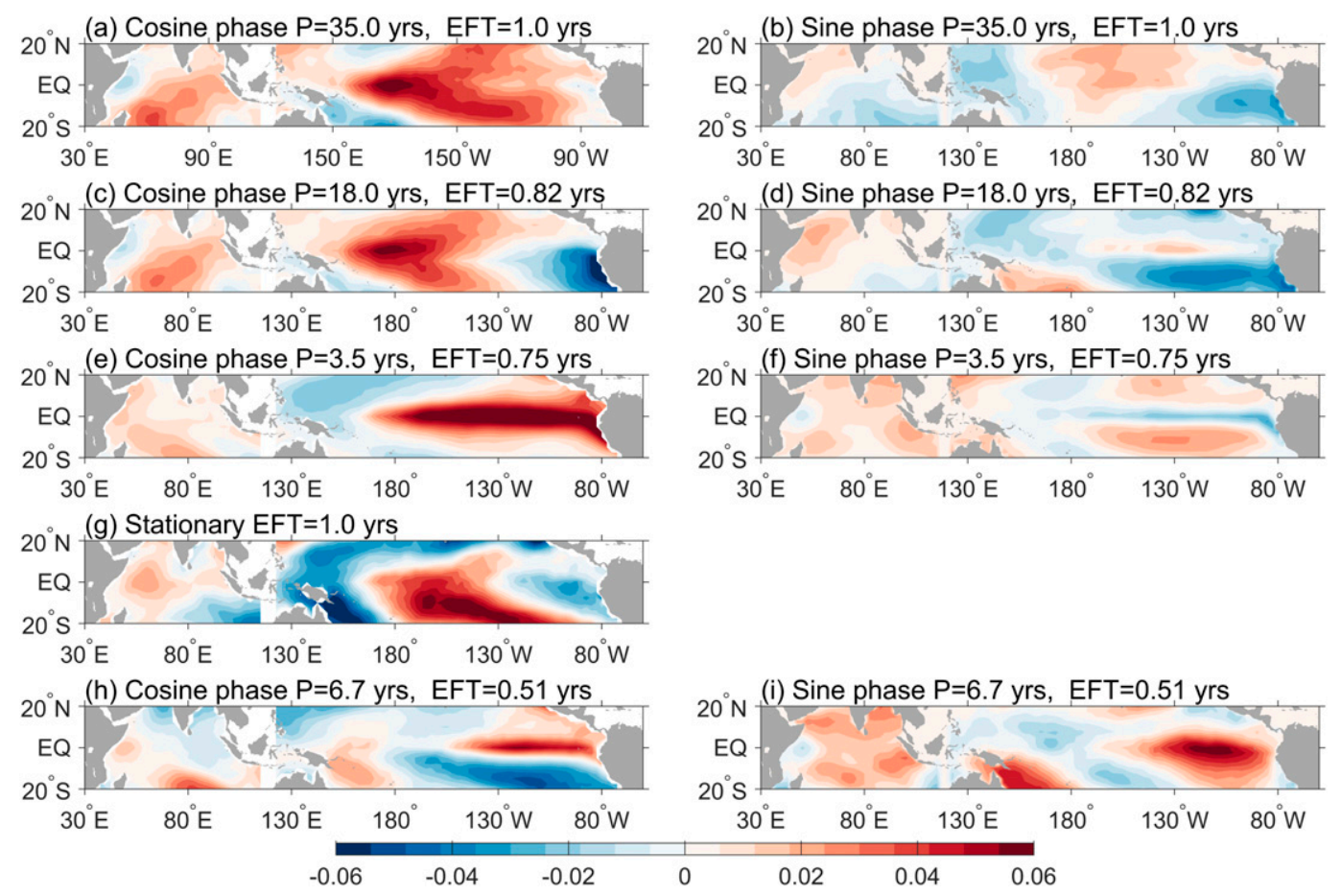

FIG. 4. Least damped empirical eigenmodes of observed SSTA after 3-month running mean within tropical Pacific and Indian Ocean in the period of 1890-2015. Eigenmodes 1-5 are ordered by decreasing $e$-folding time from the top to bottom row. Panels in the right columns are $\pi / 2$ phase after the panels on the left.

decadal eigenmodes together both project strongly on the structure that extends from the east of Madagascar maximum to the central-eastern equatorial Indian Ocean shown in the EOF1 pattern of the observed SST on decadal time scale (Figs. 2a and 3a). Note that the IPO and decadal variability of the ENSO index are highly correlated (e.g., Han et al. 2014a; Newman et al. 2016), and thus it is unclear whether or how the IPO's effect on the Indian Ocean can be treated as independent from those of ENSO.

\section{b. ENSO eigenspace}

Previous studies (Klein et al. 1999; Saji et al. 2006) suggested that interannual SSTA over the Indian Ocean is strongly influenced by ENSO. Indeed, the eigenmode 3 time series shows the strongest correlation with ENSO compared to other individual eigenmodes, with correlation coefficient 0.66 with the tropical Pacific PC1 time series. Some other eigenmodes, however, are also correlated with ENSO. Thus, as ENSO itself acts on different spatial and time scales, it is best represented by the superposition of a few eigenmodes rather than by a single eigenmode (Penland and Sardeshmukh 1995). Likewise, we might expect that ENSO's relationship with the Indian Ocean also will not be captured by a single eigenmode. For example, eigenmodes 3 and 5 are associated with quasi 3 -yr and 6-yr periodicities of ENSO (Penland and Sardeshmukh 1995; Moron et al. 1998; Compo and Sardeshmukh 2010), as they both start from weak SST anomalies in the eastern Pacific (sine phase) and further develop into strong anomalies (cosine phase). However, ENSO's relationship with the IOB appears primarily in eigenmode 3. Following Compo and Sardeshmukh (2010), we reconstruct the tropical Pacific PC1 time series using only the sum of a few eigenmodes,

$$
\tilde{E}(t)=\left[\sum_{j=1}^{N} \mathbf{u}_{j} \alpha_{j}(t)\right],
$$

where the sum is taken over eigenmodes 1, 3, and 5. Adding eigenmode 2 weakens the correlation between $\tilde{E}$ (reconstructed tropical Pacific PC1 time series) and $E$ (observed tropical Pacific PC1 time series) (not shown). The correlation between $\tilde{E}$ and $E$ is 0.81 (see Fig. 5), suggesting that the full range of ENSO variability from interannual to decadal can be approximated by the summation of these eigenmodes.

To assess the influence of ENSO, we then reconstructed all the PCs for the Indian and Pacific Oceans using 1) the selected ENSO eigenmodes and 2) the remaining eigenmodes. The comparison of their reconstructed variances is shown in Fig. 6. Note that because the eigenmodes are nonorthogonal, in some regions these variances can sum up to more than the total variance. That means in these regions, the eigenmodes are producing relative cancellation on average. In the eastern tropical Pacific, the ENSO eigenmodes alone can capture almost all SSTA variability on annual mean, interannual, and decadal time scales, with non-ENSO eigenmodes containing relatively little remaining variance. In other regions such as along the date line, within the intertropical convergence zone (ITCZ), and in the south subtropical Pacific, however, ENSO and non-ENSO modes represent roughly equivalent SSTA 


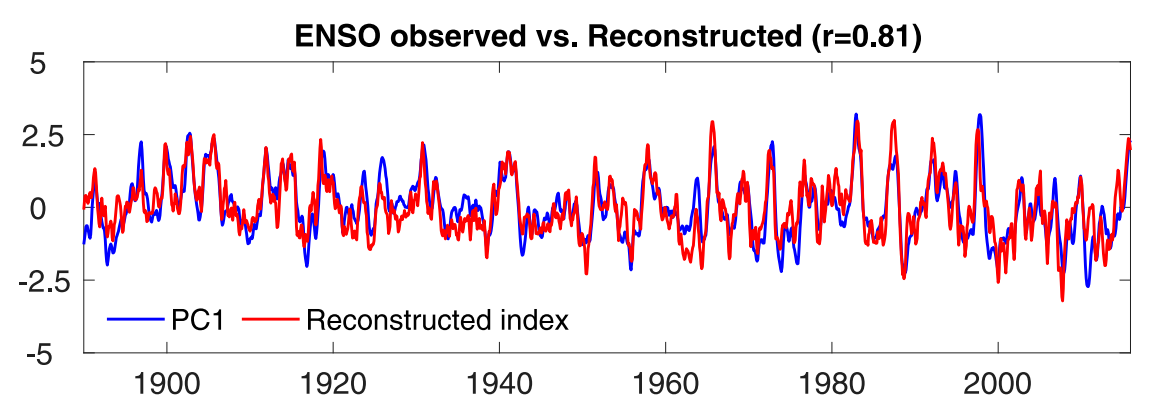

FIG. 5. Comparison of reconstructed ENSO index based on eigenmodes 1, 3, and 5 shown in Fig. 4 (red curve) and observed ENSO index (PC1 of the observed tropical Pacific SSTA; blue curve). Both indices have been normalized. The correlation coefficient between the two is 0.81 .

variance. In the Indian Ocean, both ENSO and non-ENSO modes correspond to larger variances compared to the observed (not shown). This result suggests that much of Indian Ocean SSTA variability is due to interference between ENSO and non-ENSO eigenmodes of comparable magnitudes. The impact from non-ENSO eigenmodes includes the impacts from other external climate modes and internal variability within the Indian Ocean.

In reality, the Indian Ocean can also have an active impact on the Pacific on both interannual and decadal time scales (e.g., Yu 2008; Han et al. 2014a; Zhang and Han 2018; Luo et al. 2012), and the Indian and Pacific Oceans are intimately coupled. The reconstructed IOD and SIOD indices from any combinations of the first to fifth eigenmodes do not have a high correlation $(<0.31)$ with their observed counterparts. Thus, these two modes are not simply associated with the eigenmodes shown in Fig. 4 and appear to be primarily related to the eigenmodes with shorter EFTs.

\section{c. Uncoupled eigenmodes}

To evaluate the effect of the Pacific on the Indian Ocean, we exclude the interactions between the tropical Pacific and the Indian Ocean by setting the interaction terms to zero in the dynamical operator $\mathbf{L}$ (i.e., $\mathbf{L}_{P I}=\mathbf{L}_{I P}=0$ ). Now the new derived uncoupled eigenmodes can only demonstrate spatial structures either in the Pacific or in the Indian Ocean. The leading eigenmode within the Indian Ocean only, shown in Fig. 7, is now a stationary, dipole-like pattern (Fig. 7a) that is quite similar to the IOD-like mode shown in Fig. 2. The second eigenmode pair, which has a 3.4-yr period, has a cosine phase with a similar structure to that in Fig. 4a, and Fig. 7c has a sine phase with a west-east dipole structure that follows the cosine phase such that the signal propagates from west to east across the Indian Ocean. Both modes in Fig. 7 have similar EFTs of 0.46 years, shorter than the EFTs of the leading five coupled eigenmodes shown in Fig. 4. As a result, the independent Indian Ocean eigenmodes and ENSO have different decay scales. Interestingly, the IOD-like pattern becomes more dominant without the Pacific influence (Fig. S4), consistent with the view that an IOD-like anomaly can be selfgenerated internally within the Indian Ocean air-sea coupled system as long as the thermocline off Sumatra is shallow enough to support Bjerknes feedback (Fischer et al. 2005).

\section{Diagnosis of tropical Indian-Pacific dynamical coupling}

To evaluate how Indian Ocean internal dynamics drive Indian Ocean SSTA variability (as represented by the leading three Indian Ocean PC time series shown in Fig. 3), LIM experiments are performed to obtain four "uncoupled" runs:

1) "Fully uncoupled": the tropical Pacific and the Indian Ocean are uncoupled by zeroing out the interaction terms of $\mathbf{L}\left(\mathbf{L}_{P I}=\mathbf{L}_{I P}=0\right)$, and the noise within the two basins is also uncorrelated $\left(\left\langle\boldsymbol{\xi}_{P} \boldsymbol{\xi}_{I}^{\mathrm{T}}\right\rangle\right)$. This fully uncoupled model now actually consists of two independent dynamical systems. In the tropical Pacific it is

$$
\frac{d \mathbf{x}_{P}}{d t}=\mathbf{L}_{P P} \mathbf{x}_{P}+\boldsymbol{\xi}_{P}
$$

while in the tropical Indian Ocean the evolution becomes

$$
\frac{d \mathbf{x}_{I}}{d t}=\mathbf{L}_{I I} \mathbf{x}_{I}+\boldsymbol{\xi}_{I}
$$

2) "Noise-coupled": as in the fully uncoupled model but using the original correlated noise eigenmodes (i.e., the noise effect is not decoupled). Essentially, this allows the tropical Pacific and the Indian Ocean to be coupled only on short (i.e., unpredictable subseasonal) time scales.

3) "NO $P \rightarrow I$ ": $\mathbf{L}_{I P}=0$ and $\left\langle\boldsymbol{\xi}_{P} \boldsymbol{\xi}_{I}^{\mathrm{T}}\right\rangle=0$. That is, the tropical Pacific does not force the tropical Indian Ocean $\left(\mathbf{L}_{I P}=0\right)$ but the Indian Ocean still has influence on the Pacific $\left(\mathbf{L}_{P I} \neq 0\right)$.

4) "NO $I \rightarrow P$ ": the tropical Indian Ocean does not affect the tropical Pacific (i.e., $\mathbf{L}_{P I}=0$ and $\left\langle\boldsymbol{\xi}_{P} \boldsymbol{\xi}_{I}^{\mathrm{T}}\right\rangle=0$ ) but $\mathbf{L}_{I P} \neq 0$ so that the Pacific Ocean can drive the Indian Ocean.

All four LIM sensitivity experiments were integrated forward for 126000 years using the same initial condition and time step as the "fully coupled" LIM run. The results from each LIM integration yielded a 1000-member ensemble of 126-yr 
(a) Annual Var Non-ENSO/ENSO

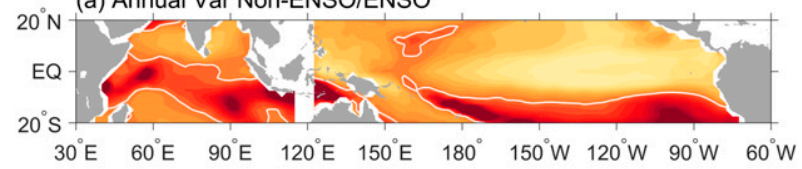

(b) Interannual Var Non-ENSO/ENSO

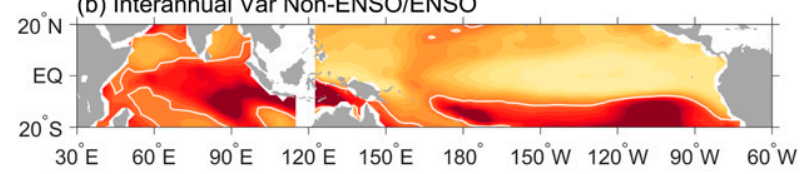

(c) Decadal Var Non-ENSO/ENSO

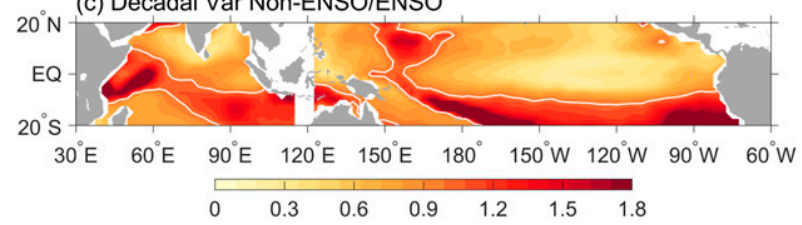

FIG. 6. Ratio distribution of SSTA variance for SSTA reconstruction using eigenmodes not dynamically linked to ENSO compared to its counterpart using eigenmodes linked to ENSO. The variance comparison of (a) annual mean SSTA, (b) interannual SSTA (annual mean subtracts 5-yr running mean), and (c) 5-yr running mean result. White contours denote the value 1 .

segments, the same length as the observed record for easier comparison. Next, we compare the partially coupled and fully uncoupled features of each predicted leading PC time series in the tropical Indian Ocean to their counterparts in the observations and fully coupled LIM integration.

\section{a. $I O B$}

Figure 8a shows the correlation between ENSO and IOB indices, using the annual mean, interannual, and decadal time scales defined in section 2 . The corresponding variances of the IOB indices are shown in Fig. 8b. The error bars illustrate the uncertainty range determined from each of the 1000 ensemble members in each LIM run. The LIM reproduces the observed interannual and decadal IOB variability (Fig. 8b), although the interannual portion of the variability is overestimated and the decadal portion is underestimated. This could reflect some deficiency of the LIM or (given the relationship between the IOB and external radiative forcing) in the method used to remove the global warming component (Frankignoul et al. 2017). Observations and the LIM have similar IOB-ENSO correlations, with simultaneous correlation coefficients of around $0.3-$ 0.4 at different time scales, confirming that the LIM captures the IOB-ENSO relationship. The LIM also captures their lead-lag relationship, where the correlation is highest $(r=0.5)$ when ENSO leads the IOB by about $4-5$ months (Fig. 9a; also see Alexander et al. 2002; Xie et al. 2009). This consistency between LIM and observations further validates the assumption that the tropical Pacific-Indian Ocean coupling mainly occurs on time scales longer than three months when constructing the LIM.

As expected, the IOB-ENSO correlation drops significantly in the uncoupled runs, especially for the fully uncoupled integration when the two basins are completely independent. (a) Stationary EFT $=0.43$ yrs

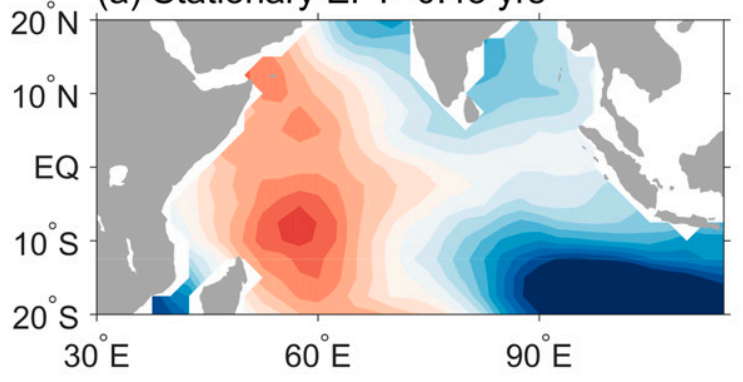

(b) Cosine phase $\mathrm{P}=3.4 \mathrm{yrs}, \mathrm{EFT}=0.46 \mathrm{yrs}$

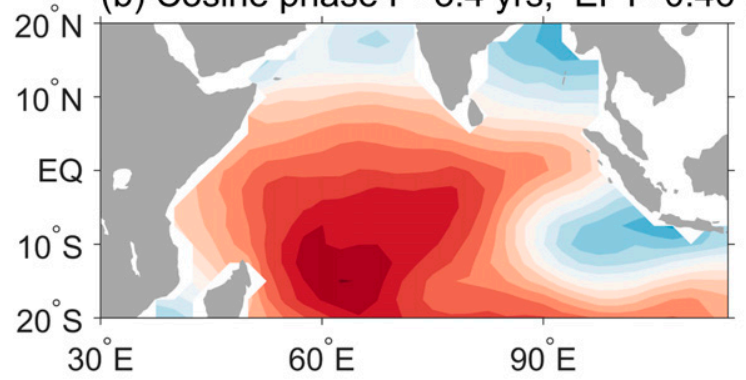

(c) Sine phase $\mathrm{P}=3.4 \mathrm{yrs}, \mathrm{EFT}=0.46 \mathrm{yrs}$

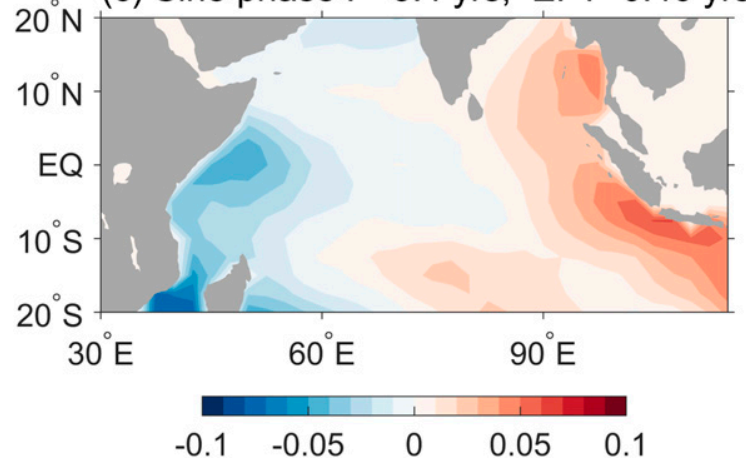

FIG. 7. The two least damped uncoupled empirical eigenmodes of SSTA within the tropical Indian Ocean only in the period of 18902015. Eigenmodes are ordered by decreasing $e$-folding time.

When the coupled noise is retained in the noise-coupled runs, IOB-ENSO correlations are still quite weak, suggesting that most of the coupling between the two ocean basins occurs on greater than seasonal time scales. Meanwhile, removing interbasin coupling decreases the IOB variance by about $25 \%$, as can be seen comparing observations and the fully coupled LIM runs to all the uncoupled runs (the noise-coupled and fully uncoupled). Therefore, the LIM shows that the IOB is strongly influenced by the Pacific, consistent with previous studies.

We then examine the IOB variability in the partially uncoupled LIM runs. When the tropical Pacific does not affect the Indian Ocean (NO $P \rightarrow I$ ), both the ENSO-IOB correlation and the IOB strength drop significantly compared to fully coupled run and observations (Fig. 8). Consistently, the significant correlation when ENSO leads the IOB by $4-5$ months disappears in NO $P \rightarrow I$. These results suggest that the IOB is largely forced by ENSO. Conversely, when there is no 
(a) Corr. between IO PC1 and PO PC1

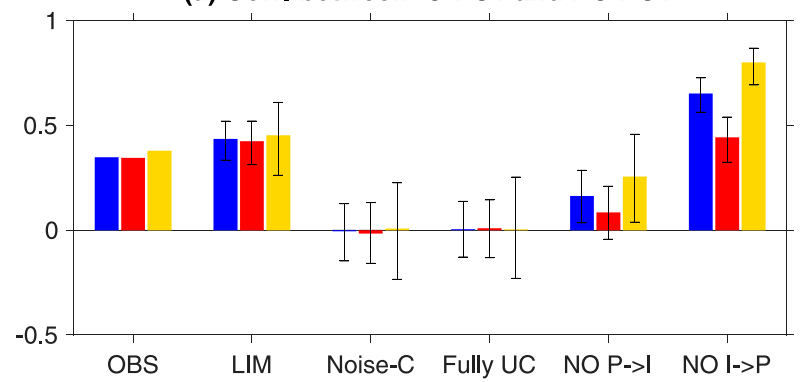

(b) Variance of IO PC1

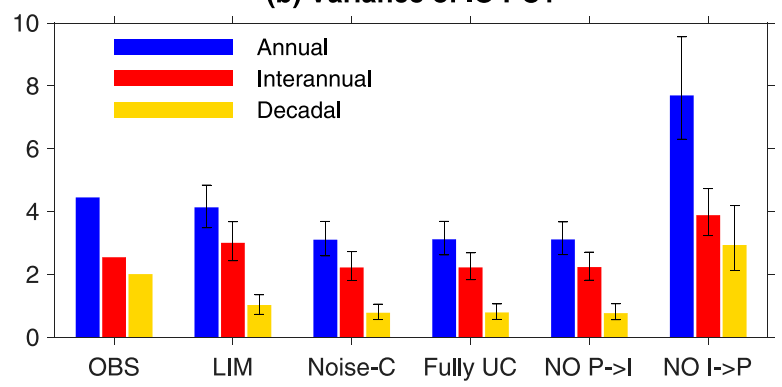

FIG. 8. (a) Correlation between ENSO (leading tropical Pacific PC) and IOB (tropical Indian Ocean PC1) for observation, "fully coupled" LIM, "noise coupled" LIM, "fully uncoupled" LIM, LIM with tropical Pacific forcing of tropical Indian Ocean removed, and LIM with tropical Indian Ocean forcing of tropical Pacific removed. The error bars represent the 10th and 90th percentile determined from the 126000 -yr run of corresponding LIM integrations. (b) As in (a), but for the variance of the IOB.

influence from the Indian Ocean on the Pacific (NO $I \rightarrow P$ ), the IOB variance increases, especially on annual and decadal (where it is tripled) time scales. Note that if the interbasin coupling is weak, the PC variance would not change much in the uncoupled run compared with fully coupled LIM. Hence, the increase in the IOB variance in the NO $I \rightarrow P$ run suggests an active role of IOB in affecting the Pacific Ocean, because the Indian Ocean can no longer leak energy to the Pacific in the NO $I \rightarrow P$ as it does in coupled LIM. Here the energy in LIM essentially represents the SSTA variance. Physically, this is consistent with previous studies, which show prominent impacts of Indian Ocean SSTA on ENSO through the atmospheric teleconnection. For instance, it has been found that the IOB warming reduces the tropical Pacific positive SSTA and therefore weakens the ENSO-IOB correlation on both interannual (Wu and Kirtman 2004; Kug and Kang 2006; Xie et al. 2009) and decadal (Luo et al. 2012; Han et al. 2014a) time scales. This is likely the reason why the IOB-ENSO correlation increases in NO $I \rightarrow P$ when there is no IOB damping effect on ENSO, particularly on annual and decadal time scales.

\section{b. IOD-like mode}

Figure 10 shows the results for the IOD-like mode in the LIM sensitivity experiments. The observed and fully coupled LIM runs demonstrate similar IOD-ENSO correlations for annual means around 0.4 , but the LIM underestimates the correlation on interannual time scales and overestimates the correlation on decadal time scales, although the uncertainty among the ensemble members is also quite large. Additionally, the LIM captures the observed percentages of interannual and decadal variances of the IOD-like mode (Fig. 10b) and the IOD-ENSO lead-lag relationship (Fig. 9b), including the higher correlation values when the IOD-like mode leads ENSO (Krishnamurthy and Krishnamurthy 2016).

Overall the variance of the IOD-like mode is not significantly changed by decoupling with the Pacific (Fig. 10b). This suggests that the IOD-like mode could exist and fluctuate independently without any Pacific influence on both interannual (Fischer et al. 2005; Yang et al. 2015) and decadal time scales (Tozuka et al. 2007; Han et al. 2014b), which is different from the IOB mode. As a result, the IOD-like mode in the uncoupled runs becomes the leading EOF mode of SSTA in the (a) IOB-ENSO

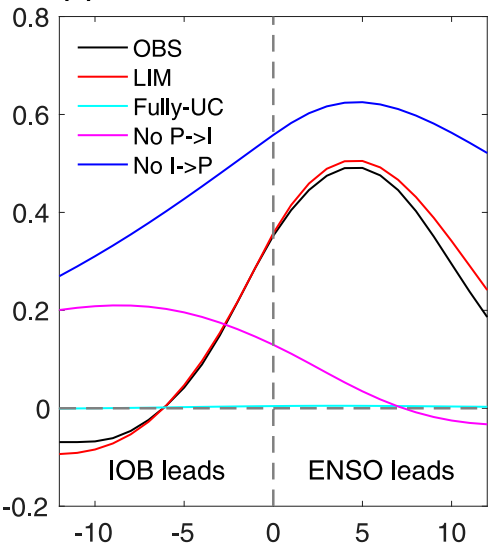

(b) IOD-ENSO

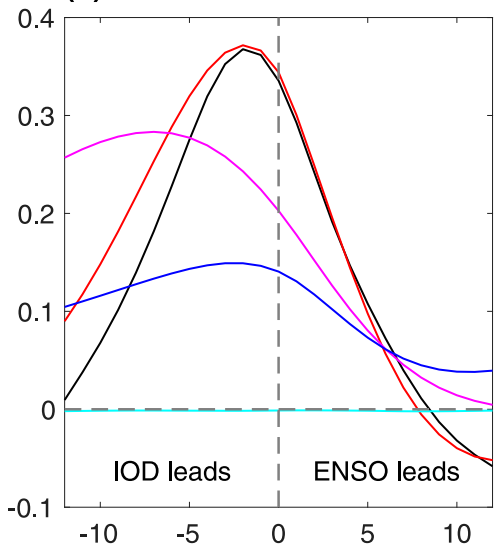

(c) PC3-ENSO

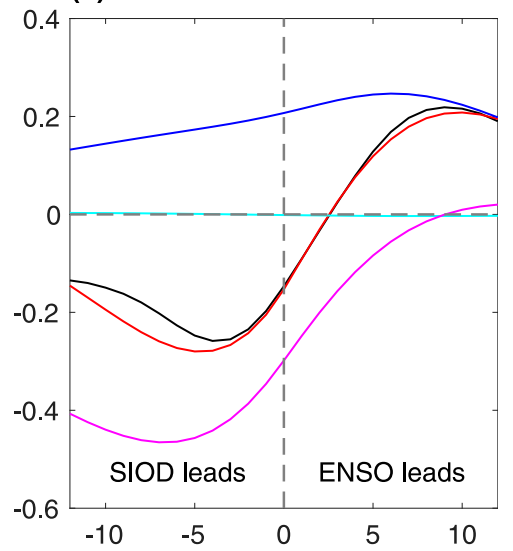

FIG. 9. Lead-lag correlation between ENSO (PC1 of 3-month running mean tropical Pacific SSTA) and the (a) IOB (PC1 of 3-month running mean tropical Indian Ocean SSTA), (b) IOD-like (PC2 of 3-month running mean tropical Indian Ocean SSTA), and (c) PC3 of 3-month running mean tropical Indian Ocean SSTA for observation, "fully coupled" LIM, "fully uncoupled" LIM, LIM with tropical Pacific forcing of tropical Indian Ocean removed, and LIM with tropical Indian Ocean forcing of the tropical Pacific removed. 
(a) Corr. between IO PC2 and PO PC1

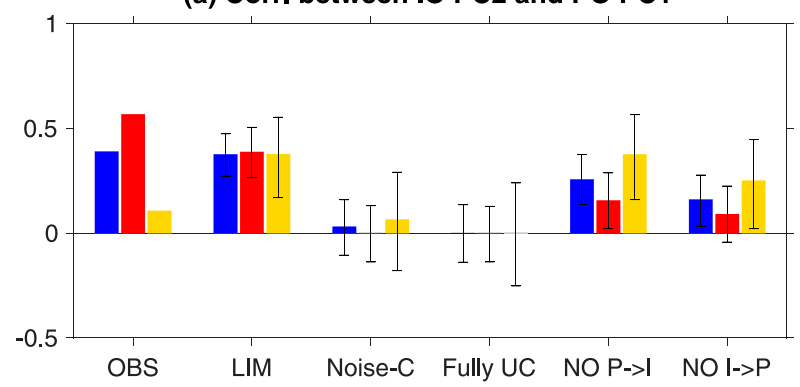

(b) Variance of IO PC2

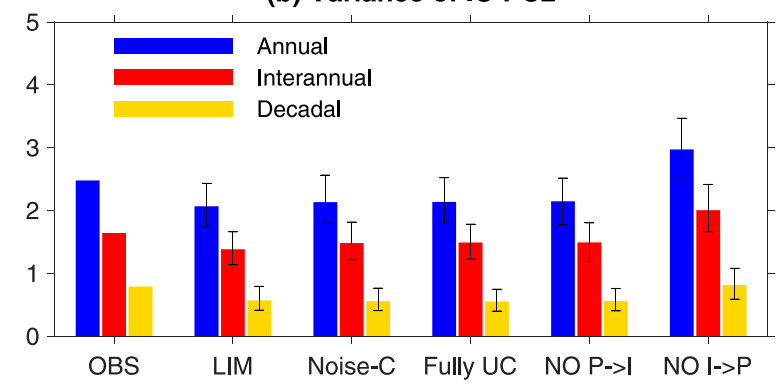

FIG. 10. (a) As in Fig. 8a, but for correlation between ENSO and the IOD-like mode (tropical Indian Ocean PC2). (b) As in Fig. 8b, but for the IOD-like mode.

tropical Indian Ocean (see Fig. S4), since the IOB is weaker without the Pacific influence.

Unlike the IOB, the IOD-ENSO correlation peaks when the IOD-like mode leads by 2 months (Fig. 9b), suggesting that the primary process for the coupling between the two is for the IODlike mode to actively impact the Pacific. Indeed, the IOD-ENSO correlation drops and the variance of the IOD-like mode increases significantly in the NO $I \rightarrow P$ run when the Indian Ocean cannot leak energy to the tropical Pacific (Fig. 10). On the other hand, there is a secondary effect of return forcing from the Pacific to affect the evolution of the IOD-like mode, because the IOD-ENSO correlation decreases in the NO $P \rightarrow I$ run although it is not as significant as in NO $I \rightarrow P$ (Fig. 10a), and their lead-lag correlation becomes less focused (Fig. 9b). These results suggest the important role of the Indo-Pacific coupling in determining the observed IOD-ENSO relationship. It is worth noting that the role of ENSO in influencing the IOD-like mode is weak on decadal time scales, since removing the Pacific influence in the NO $P \rightarrow I$ run impacts neither the IOD-ENSO correlation nor the variance of the IOD-like mode.

\section{c. $S I O D$}

The PC3 (partly associated with the SIOD) and ENSO are weakly anticorrelated in both observations and the LIM, at all three time scales (Fig. 11). In fact, the LIM confidence intervals suggest the possibility that there is no significant simultaneous correlation between PC3 and ENSO. This simultaneous correlation is somewhat misleading, however, since the PC3 and ENSO are almost in quadrature in both observations and the fully coupled LIM (Fig. 9c); therefore, the PC3-ENSO (a) Corr. between IO PC3 and PO PC1

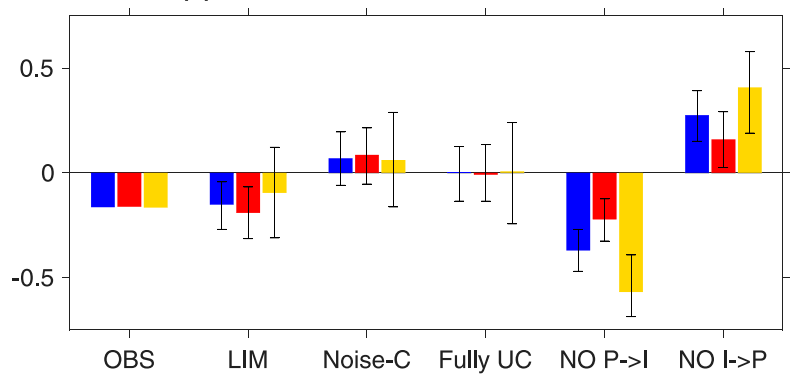

(b) Variance of $10 \mathrm{PC3}$

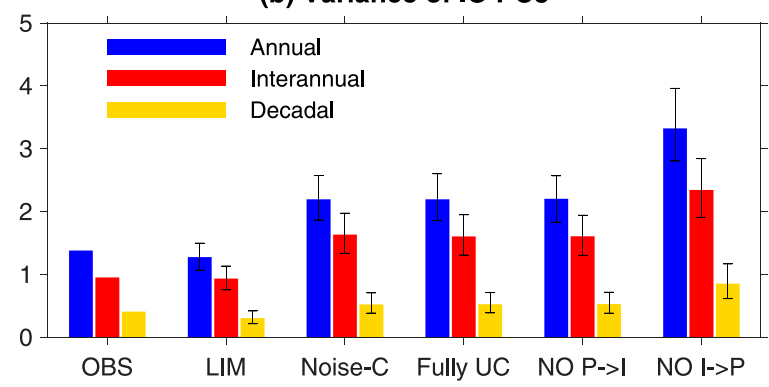

FIG. 11. (a) As in Fig. 8a, but for correlation between ENSO and tropical Indian Ocean PC3. (b) As in Fig. 8b, but for PC3.

relationship is unlike IOB or the IOD-like mode, and they appear to represent two phases of the same mode associated with Indo-Pacific interbasin coupling, with a period on the order of about 2 years, possibly related to the quasi-2-yr ENSO triggering an SIOD-like pattern in the Indian Ocean. However, it is worth noting that the PC3-ENSO correlation is much weaker compared to IOB and IOD-like mode, and therefore only a small component of EOF3 is coupled with ENSO.

Without Indo-Pacific interactions (noise-coupled and fully uncoupled run), the PC3 variance increases by $70 \%$ at all time scales compared to its counterpart in the fully coupled run (Fig. 11b), which is different from the results for the IOB and IOD-like mode. Furthermore, a similar increase of the PC3 variance is found in the NO $P \rightarrow I$ (Fig. 10b). These results suggest that the PC3 is primarily generated by the Indian Ocean internal coupled processes. The enhanced PC3 variance is even more significant in the NO $I \rightarrow P$ run, because again the Indian Ocean cannot leak energy to the Pacific in this experiment.

\section{d. Overall variance}

Finally, to evaluate the effect of Indian-Pacific coupling on the overall spatial pattern of Indian Ocean SST variance, Fig. 12 shows the ratio of SSTA variance from the fully coupled LIM compared to the fully uncoupled and partially uncoupled (NO $P \rightarrow I$ and NO $I \rightarrow P$ ) LIM runs. In the fully uncoupled run, the variance of annual mean SST over the Bay of Bengal, central Indian Ocean, and eastern basin off the west coast of Sumatra is increased compared to the fully coupled run, and is decreased elsewhere. Results are very similar for interannual and decadal time scales. Compared to the fully uncoupled run, results are nearly identical when only the Pacific influences on 

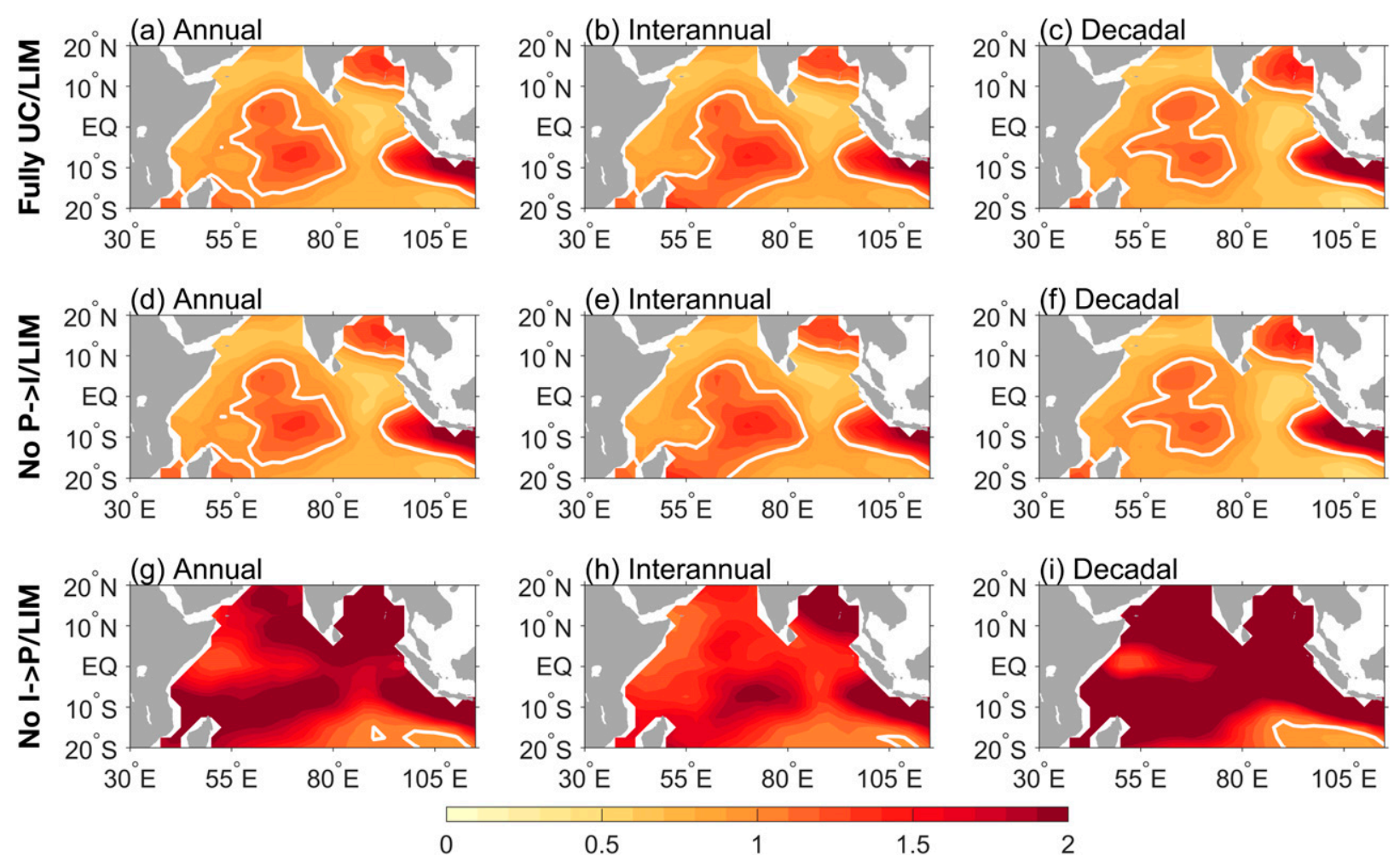

FIG. 12. (a)-(c) SSTA variance ratio distribution between the uncoupled LIM runs (i.e., "fully uncoupled") and the "fully coupled" LIM run (the variance of the uncoupled runs divided by that of the fully coupled run). (d)-(f) As in (a)-(c), but for NO $P \rightarrow I$. (g)-(i) As in (a)-(c), but for NO $I \rightarrow P$. The variance comparison of (left) monthly SSTA based annual mean SSTA, (center) interannual SSTA variance, and (right) 5-yr running mean SSTA. White contours denote the value 1 .

the Indian Ocean are excluded (Figs. 12a-f), suggesting that the Pacific impact indeed plays an important role in forcing Indian Ocean SST variability.

On the other hand, the variance ratio increases significantly in the NO $I \rightarrow P$ run compared to the fully coupled run at seasonal-to-decadal time scales (Figs. 12g-i). For annual mean SST, the variance ratio is greater than 1 across the entire tropical Indian Ocean, with higher values in north Indian Ocean, the thermocline ridge region in the southwest Indian Ocean, and eastern basin off Sumatra. For interannual (decadal) time scales, the variance ratio distribution shows similar spatial patterns to the annual mean SST results but with smaller (larger) values. The stronger Indian Ocean SST variability in the NO $I \rightarrow P$ run compared to the fully coupled run is because the Indian Ocean cannot lose energy to the Pacific. If the Indian Ocean only passively responded to Pacific forcing, there should be no SSTA amplitude increase in the NO $I \rightarrow P$ LIM run. Therefore, the Indo-Pacific coupling is a two-way interaction, with both the Indian Ocean's influence on the Pacific and the Pacific's return effect on the Indian Ocean being important.

\section{Summary and discussion}

In this study, we performed a comprehensive analysis of Indian Ocean SSTA variability and its relationship with Pacific SSTA variability during 1890-2015. In particular, we examined relationships between ENSO and the first three EOF modes of Indian Ocean SSTA (i.e., the IOB, the IOD-like mode, and a third mode that is partly associated with the SIOD) on both interannual and decadal time scales, by conducting a hierarchy of LIM experiments with full coupling, partial coupling, and full decoupling between the tropical Pacific and Indian Ocean SSTA. The main findings are summarized below.

The LIM successfully captured the essence of observed SSTA spatial distributions and the temporal evolution of the leading PCs in the tropical Indian Ocean, including their observed relationships with ENSO. The sensitivity experiments of the LIM provide estimates for the influence of interbasin interaction. Overall, the Indian Ocean internal processes can generate interannual-to-decadal SSTA, and its SST variance is enhanced by coupling to the Pacific, especially in the central tropical Indian Ocean and eastern basin off the Sumatra coast (cf. the fully coupled and uncoupled LIM runs). With no Indian Ocean impact on the Pacific (NO $I \rightarrow P$ run), Indian Ocean SSTA has larger magnitudes compared to the fully coupled run, suggesting that the Indian Ocean loses energy to the Pacific; meanwhile, the Pacific return effect is crucial for maintaining the balance of processes that generate the observed Indian Ocean SSTA. These results demonstrate that the Indo-Pacific Ocean is a closely coupled system.

The IOB represents the basin-scale (same sign) SSTA in the tropical Indian Ocean and is the leading EOF of observed 
SSTA (with global SST trend pattern removed). The observed IOB variability results primarily from the Pacific influence from ENSO; without the Pacific influence (NO $P \rightarrow I$ ), the IOB variance decreases by $25 \%$, and the simultaneous IOBENSO correlation decreases dramatically at all time scales. The IOB in turn affects the tropical Pacific, as it weakens the eastern Pacific SSTA. Indeed, the IOB variance increases in NO $I \rightarrow P$ when the Indian Ocean cannot leak energy to the tropical Pacific, especially on annual and decadal time scales.

Unlike the IOB, the IOD-like mode can exist independently from ENSO, and the IOD-ENSO correlation peaks when the IOD-like mode leads by 2 months. As a result, the variance of the IOD-like mode is not significantly changed in the uncoupled runs. However, decoupling from the tropical Pacific leads to a weaker and less focused IOD-ENSO correlation, suggesting that the returning effect from ENSO affects the evolution of the IOD-like mode, but this effect is rather weak on decadal time scale. While our results are consistent with previous modeling studies suggesting that the IOD is an internal Indian ocean mode (i.e., in the fully uncoupled LIM run it is the leading EOF mode and its variance does not change) (Baquero-Bernal et al. 2002; Fischer et al. 2005; Yu and Lau 2005; Behera et al. 2006), new insight provided by our LIM runs suggests that in the real climate system the observed IODlike mode is a result of two-way interaction with ENSO.

The PC3 is partly associated with the SIOD, but other processes (e.g., the Asian-Australian monsoon) may also play a role in contributing to this mode. Unlike IOB and the IOD-like mode, PC3 and ENSO exhibits a quadrature relationship, and their lead-lag correlation is relatively weak. Hence, only a small component of PC3 is coupled with ENSO. Indeed, decoupling from ENSO actually leads to higher PC3 variance at all time scales, suggesting that PC3 is primarily generated by Indian Ocean internal processes.

Another climate mode in the Indian Ocean is the Ningaloo Niño, which is characterized by strong SSTAs off the west coast of Australia (Feng et al. 2013). However, Ningaloo Niño is not considered in this study since we focus on the tropical Indian Ocean, yet it has been shown that the Ningaloo Niño is intimately connected with the central tropical Pacific through both the atmospheric and oceanic connections (Zhang and Han 2018). A future study targeting at the role of the Ningaloo Niño in Indo-Pacific interbasin interactions using the LIM is warranted.

The response of the Pacific to the interbasin coupling processes in LIM also requires investigation. Here we simply compare the ENSO index in different runs as an example (see Fig. S5). The uncoupled runs show stronger variation for the interannual-to-decadal Pacific SSTA compared to the observed, which could be due to the exclusion of the IOB damping effect on eastern tropical Pacific SSTA (Fig. 8a) (Santoso et al. 2012; Han et al. 2014a; Kajtar et al. 2017; Xie et al. 2009; Zhang and Karnauskas 2017). However, this result is different from previous studies that found weaker Pacific SSTA variance when decoupled from the tropical Indian Ocean (e.g., Wu and Kirtman 2004). This discrepancy could occur because we only use PC1 in this study to represent ENSO, while ENSO is a diverse climate phenomenon that may not be fully captured by a single EOF mode (e.g., Vimont et al. 2014). On the other hand, when the Pacific impact on the Indian Ocean is turned off, the Pacific SSTA variance increases because it can no longer lose energy to the Indian Ocean. In the NO $I \rightarrow P$ run, the Pacific SSTA variance resumes to the level for the fully uncoupled run. These results further support the important ENSO influences on the Indian Ocean SSTA variability.

Since we removed the global-mean SST time series related SST patterns from the observations prior to our analyses, the role of the long-term variation is worthy of further discussion. The Indo-Pacific coupled climate system, with its large heat capacity and strong dynamical effects, plays an important role in regulating the global SST warming rates, while the global warming signal also comprises a major part of the Indo-Pacific variation (Ihara et al. 2008; Zheng et al. 2010; Kosaka and Xie 2016; Zhang 2016). Additionally, Indian Ocean warming modulates Pacific climate variability and climate change signals (Luo et al. 2012; Han et al. 2014a; Zhang et al. 2019a). Our results show that when we remove SST anomalies related to global mean temperature trends, the Indian Ocean basinaveraged SSTA variance decreased by $70 \%-80 \%$ (see Fig. S2). In particular, the original IOB is strongly related to the longterm global SST variability in the observed dataset without removing global warming regressed signals. The IOB drops approximately $81 \%$ of its variability when the global mean temperature signal is removed, and further loses another $5 \%$ when the Indian Ocean variability becomes independent from the Pacific (cf. the fully coupled and fully uncoupled LIM runs). The remaining $14 \%$ of the variability represents the inherent variation of IOB in the Indian Ocean. Similarly, we also tested the impact on the IOD from the global mean temperature trend but very small change of its amplitude was found ( $\sim 8 \%$ decrease), which further proved the largely independent behavior of IOD in the Indo-Pacific system.

This study represents an empirical attempt to quantify the coupled dynamics between the tropical Pacific and Indian Ocean basins based solely on their observed SSTAs. This means that the contribution of all other atmospheric and oceanic processes to their dynamics, as well as interactions with other ocean domains (e.g., the Atlantic Ocean), must be represented by the dynamical operator of the SSTAs alone. While this can be a usable approximation (Penland and Sardeshmukh 1995), it is not an ideal one (Newman et al. 2011), and it is possible that some aspects of the dynamics are not cleanly separated between the basins as a result. Additionally, as an empirical model, the LIM is limited by the training data used. In our study, the 126-yr observational SSTA record could well be too short and/or inadequate to determine the accurate linear parameters for decadal variability, and this problem would only be worsened if we were to include additional climate variables or to include seasonality of the dynamical operator. Also, of course, the LIM presumes that seasonal SSTA evolution in the Indo-Pacific system can be well described using multivariate linear dynamics where rapidly decorrelating nonlinearities are represented by white noise forcing. However, if nonlinear effects exist in the Indo-Pacific coupling that cannot be simply represented by additive white noise (Cai 
and Qiu 2013; Mukhin et al. 2015); it would impact interpretation of the LIM results (Newman and Sardeshmukh 2017; Ding et al. 2018). Regardless of these limitations, our LIM analysis agrees with existing studies on the IOB-ENSO relationship, and sheds some light on the importance of IOD and SIOD on ENSO. Shin et al. (2020) recently developed a new version of LIM that takes the seasonality into consideration, and we will test our results using the new LIM in a future study. Moreover, recent studies suggest that LIM skill is comparable to CGCMs for interannual to decadal variability research, while LIM is more applicable to diagnose separated dynamics for its usability. We also plan to use this technique on CGCM output [e.g., phase 6 of the Coupled Model Intercomparison Project (CMIP6)]. How the Indo-Pacific two-way interactions are represented by the CGCMs compared to observations is a topic for further investigation.

Acknowledgments. We thank the anonymous reviewers for their constructive and helpful comments. The research is supported by NSF AGS 1446480.

\section{REFERENCES}

Alexander, M. A., I. Bladé, M. Newman, J. R. Lanzante, N.-C. Lau, and J. D. Scott, 2002: The atmospheric bridge: The influence of ENSO teleconnections on air-sea interaction over the global oceans. J. Climate, 15, 2205-2231, https://doi.org/10.1175/15200442(2002)015<2205:TABTIO >2.0.CO;2.

Allan, R., and Coauthors, 2001: Is there an equatorial Indian Ocean SST dipole independent of the El Niño-Southern Oscillation? CLIVAR Exchanges, No. 6, International CLIVAR Project Office, Southampton, United Kingdom, $17-18$.

Baquero-Bernal, A., M. Latif, and S. Legutke, 2002: On dipole like variability of sea surface temperature in the tropical Indian Ocean. J. Climate, 15, 1358-1368, https://doi.org/10.1175/15200442(2002)015<1358:ODVOSS > 2.0.CO;2.

Behera, S. K., and T. Yamagata, 2001: Subtropical SST dipole events in the southern Indian Ocean. Geophys. Res. Lett., 28, 327-330, https://doi.org/10.1029/2000GL011451.

_ J. J. Luo, S. Masson, S. A. Rao, H. Sakuma, and T. Yamagata, 2006: A CGCM study on the interaction between IOD and ENSO. J. Climate, 19, 1688-1705, https://doi.org/10.1175/ JCLI3797.1.

Cai, W., and Y. Qiu, 2013: An observation-based assessment of nonlinear feedback processes associated with the Indian Ocean dipole. J. Climate, 26, 2880-2890, https://doi.org/10.1175/JCLID-12-00483.1.

Cavanaugh, N. R., T. Allen, A. Subramanian, B. Mapes, H. Seo, and A. J. Miller, 2014: The skill of atmospheric linear inverse models in hindcasting the Madden-Julian oscillation. Climate Dyn., 44, 897-906, https://doi.org/10.1007/s00382-014-2181-x.

Chang, P., and Coauthors, 2006: Climate fluctuations of tropical coupled systems-The role of ocean dynamics. J. Climate, $\mathbf{1 9}$, 5122-5174, https://doi.org/10.1175/JCLI3903.1.

Cheng, L., K. E. Trenberth, J. Fasullo, T. Boyer, J. Abraham, and J. Zhu, 2017: Improved estimates of ocean heat content from 1960 to 2015. Sci. Adv., 3, e1601545, https://doi.org/10.1126/ sciadv.1601545.

Compo, G. P., and P. D. Sardeshmukh, 2010: Removing ENSOrelated variations from the climate record. J. Climate, 23, 1957-1978, https://doi.org/10.1175/2009JCLI2735.1.
Dee, D. P., and Coauthors, 2011: The ERA-Interim reanalysis: Configuration and performance of the data assimilation system. Quart. J. Roy. Meteor. Soc., 137, 553-597, https://doi.org/ 10.1002/qj.828.

Deepa, J. S., C. Gnanaseelan, R. Kakatkar, A. Parekh, and J. S. Chowdary, 2018: The interannual sea level variability in the Indian Ocean as simulated by an ocean general circulation model. Int. J. Climatol., 38, 1132-1144, https://doi.org/10.1002/ joc.5228.

- _ S. Mohapatra, J. S. Chowdary, A. Karmakar, R. Kakatkar, and A. Parekh, 2019: The tropical Indian Ocean decadal sea level response to the Pacific Decadal Oscillation forcing. Climate Dyn., 52, 5045-5058, https://doi.org/10.1007/ s00382-018-4431-9.

Desbruyères, D., E. L. McDonagh, B. A. King, and V. Thierry, 2017: Global and full-depth ocean temperature trends during the early twenty-first century from Argo and repeat hydrography. J. Climate, 30, 1985-1997, https://doi.org/10.1175/JCLID-16-0396.1.

Ding, H., M. Newman, M. A. Alexander, and A. T. Wittenberg, 2018: Skillful climate forecasts of the tropical Indo-Pacific Ocean using model-analogs. J. Climate, 31, 5437-5459, https:// doi.org/10.1175/JCLI-D-17-0661.1.

Dong, L., and M. J. McPhaden, 2016: Interhemispheric SST gradient trends in the Indian Ocean prior to and during the recent global warming hiatus. J. Climate, 29, 9077-9095, https:// doi.org/10.1175/JCLI-D-16-0130.1.

_ , and - 2017: Why has the relationship between Indian and Pacific Ocean decadal variability changed in recent decades? J. Climate, 30, 1971-1983, https://doi.org/10.1175/JCLI-D-160313.1.

—, T. Zhou, A. Dai, F. Song, B. Wu, and X. Chen, 2016: The footprint of the inter-decadal Pacific oscillation in Indian Ocean sea surface temperatures. Sci. Rep., 6, 21251, https:// doi.org/10.1038/srep21251.

Du, Y., S. P. Xie, Y. L. Yang, X. T. Zheng, L. Liu, and G. Huang, 2013: Indian Ocean variability in the CMIP5 multimodel ensemble: The basin mode. J. Climate, 26, 7240-7266, https:// doi.org/10.1175/JCLI-D-12-00678.1.

Feng, M., C. Böning, A. Biastoch, E. Behrens, E. Weller, and Y. Masumoto, 2011: The reversal of the multi-decadal trends of the equatorial Pacific easterly winds, and the Indonesian Throughflow and Leeuwin Current transports. Geophys. Res. Lett., 38, L11604, https://doi.org/10.1029/2011GL047291.

— M. M. McPhaden, S. P. Xie, and J. Hafner, 2013: La Niña forces unprecedented Leeuwin Current warming in 2011. Sci. Rep., 3, 1277, https://doi.org/10.1038/srep01277.

Fischer, A. S., P. Terray, E. Guilyardi, S. Gualdi, and P. Delecluse, 2005: Two independent triggers for the Indian Ocean dipole/ zonal mode in a coupled GCM. J. Climate, 18, 3428-3449, https://doi.org/10.1175/JCLI3478.1.

Frankignoul, C., G. Gastineau, and Y. O. Kwon, 2017: Estimation of the SST response to anthropogenic and external forcing and its impact on the Atlantic multidecadal oscillation and the Pacific decadal oscillation. J. Climate, 30, 9871-9895, https:// doi.org/10.1175/JCLI-D-17-0009.1.

Giese, B. S., H. F. Seidel, G. P. Compo, and P. D. Sardeshmukh, 2016: An ensemble of ocean reanalyses for 1815-2013 with sparse observational input. J. Geophys. Res. Oceans, 121, 6891-6910, https://doi.org/10.1002/2016JC012079.

Gordon, A. L., and R. A. Fine, 1996: Pathways of water between the Pacific and Indian Oceans in the Indonesian seas. Nature, 379, 146-149, https://doi.org/10.1038/379146a0. 
Han, W., and Coauthors, 2014a: Intensification of decadal and multi-decadal sea level variability in the western tropical Pacific during recent decades. Climate Dyn., 43, 1357-1379, https://doi.org/10.1007/s00382-013-1951-1.

_ - J. Vialard, M. J. McPhaden, T. Lee, Y. Masumoto, M. Feng, and W. P. M. de Ruijter, 2014b: Indian Ocean decadal variability: A review. Bull. Amer. Meteor. Soc., 95, 1679-1703, https://doi.org/10.1175/BAMS-D-13-00028.1.

—, D. Stammer, G. Meehl, A. Hu, F. Sienz, and L. Zhang, 2018: Multi-decadal trend and decadal variability of the regional sea level over the Indian Ocean since the 1960s: Roles of climate modes and external forcing. Climate, 6, 51, https://doi.org/ 10.3390/cli6020051.

Hasselmann, K., 1976: Stochastic climate models. Part I. Theory. Tellus, 28, 473-485, https://doi.org/10.3402/tellusa.v28i6. 11316.

Hermes, J. C., and C. J. C. Reason, 2005: Ocean model diagnosis of interannual coevolving SST variability in the south Indian and South Atlantic Oceans. J. Climate, 18, 2864-2882, https:// doi.org/10.1175/JCLI3422.1.

Hirahara, S., M. Ishii, and Y. Fukuda, 2014: Centennial-scale sea surface temperature analysis and its uncertainty. J. Climate, 27, 57-75, https://doi.org/10.1175/JCLI-D-12-00837.1.

Hirst, A. C., and J. S. Godfrey, 1993: The role of Indonesian Throughflow in a global ocean GCM. J. Phys. Oceanogr., 23, 1057-1086, https://doi.org/10.1175/1520-0485(1993)023<1057: TROITI $>2.0$. CO;2.

Huang, B., and J. L. Kinter III, 2002: Interannual variability in the tropical Indian Ocean. J. Geophys. Res., 107, 3199, https:// doi.org/10.1029/2001JC001278.

— , and J. Shukla, 2007: Mechanisms for the interannual variability in the tropical Indian Ocean. Part I: The role of remote forcing from the tropical Pacific. J. Climate, 20, 2917-2936, https://doi.org/10.1175/JCLI4151.1.

— , and Coauthors, 2015: Extended reconstructed sea surface temperature version 4 (ERSST.v4). Part I: Upgrades and intercomparisons. J. Climate, 28, 911-930, https://doi.org/ 10.1175/JCLI-D-14-00006.1.

Hurrell, J. W., J. J. Hack, D. Shea, J. M. Caron, and J. Rosinski, 2008: A new sea surface temperature and sea ice boundary dataset for the Community Atmosphere Model. J. Climate, 21, 5145-5153, https://doi.org/10.1175/2008JCLI2292.1.

Ihara, C., Y. Kushnir, and M. A. Cane, 2008: Warming trend of the Indian Ocean SST and Indian Ocean dipole from 1880 to 2004. J. Climate, 21, 2035-2046, https://doi.org/10.1175/ 2007JCLI1945.1.

Izumo, T., M. Lengaigne, J. Vialard, J. J. Luo, T. Yamagata, and G. Madec, 2014: Influence of Indian Ocean dipole and Pacific recharge on following year's El Niño: Interdecadal robustness. Climate Dyn., 42, 291-310, https://doi.org/10.1007/s00382-0121628-1.

Just, W., H. Kantz, C. Rödenbeck, and M. Helm, 2001: Stochastic modelling: Replacing fast degrees of freedom by noise. J. Phys. Math. Gen., 34, 3199-3213, https://doi.org/10.1088/ 0305-4470/34/15/302.

Kajtar, J. B., A. Santoso, M. H. England, and W. Cai, 2017: Tropical climate variability: Interactions across the Pacific, Indian, and Atlantic Oceans. Climate Dyn., 48, 2173-2190, https://doi.org/10.1007/s00382-016-3199-z.

Kataoka, T., T. Tozuka, Y. Masumoto, and T. Yamagata, 2012: The Indian Ocean subtropical dipole mode simulated in the CMIP3 models. Climate Dyn., 39, 1385-1399, https://doi.org/ 10.1007/s00382-011-1271-2.
Klein, S. A., B. J. Soden, and N.-C. Lau, 1999: Remote sea surface temperature variations during ENSO: Evidence for a tropical atmospheric bridge. J. Climate, 12, 917-932, https://doi.org/ 10.1175/1520-0442(1999)012<0917:RSSTVD>2.0.CO;2.

Kosaka, Y., and S. P. Xie, 2016: The tropical Pacific as a key pacemaker of the variable rates of global warming. Nat. Geosci., 9, 669-673, https://doi.org/10.1038/ngeo2770.

Krishnamurthy, L., and V. Krishnamurthy, 2016: Decadal and interannual variability of the Indian Ocean SST. Climate Dyn., 46, 57-70, https://doi.org/10.1007/s00382-015-2568-3.

Kug, J.-S., and I.-S. Kang, 2006: Interactive feedback between ENSO and the Indian Ocean. J. Climate, 19, 1784-1801, https://doi.org/10.1175/JCLI3660.1.

Lau, N. C., and M. J. Nath, 2004: Coupled GCM simulation of atmosphere-ocean variability associated with zonally asymmetric SST changes in the tropical Indian Ocean. J. Climate, 17, 245-265, https://doi.org/10.1175/15200442(2004)017<0245:CGSOAV>2.0.CO;2.

Lee, S.-K., W. Park, M. O. Baringer, A. L. Gordon, B. Huber, and Y. Liu, 2015: Pacific origin of the abrupt increase in Indian Ocean heat content during the warming hiatus. Nat. Geosci., 8, 445-449, https://doi.org/10.1038/ngeo2438.

Li, Y., W. Han, and L. Zhang, 2017: Enhanced decadal warming of the southeast Indian Ocean during the recent global surface warming slowdown. Geophys. Res. Lett., 44, 9876-9884, https://doi.org/10.1002/2017GL075050.

,,-- A. Hu, G. A. Meehl, and F. Wang, 2018: Multidecadal changes of the upper Indian Ocean heat content during 19652016. J. Climate, 31, 7863-7884, https://doi.org/10.1175/JCLID-18-0116.1.

Liu, W., and Coauthors, 2015: Extended Reconstructed Sea Surface Temperature version 4 (ERSST.v4): Part II. Parametric and structural uncertainty estimations. J. Climate, 28, 931-951, https://doi.org/10.1175/JCLI-D-14-00007.1.

Loschnigg, J., G. A. Meehl, P. J. Webster, J. M. Arblaster, and G. P. Compo, 2003: The Asian monsoon, the tropospheric biennial oscillation, and the Indian Ocean zonal mode in the NCAR CSM. J. Climate, 16, 1617-1642, https://doi.org/10.1175/15200442(2003)016<1617:TAMTTB > 2.0.CO;2.

Luo, J.-J., W. Sasaki, and Y. Masumoto, 2012: Indian Ocean warming modulates Pacific climate change. Proc. Natl. Acad. Sci. USA, 109, 18701-18 706, https://doi.org/10.1073/pnas.1210239109.

Meyers, G., 1996: Variation of Indonesian throughflow and the El Niño-Southern Oscillation. J. Geophys. Res., 101, 1225512 263, https://doi.org/10.1029/95JC03729.

— , P. McIntosh, L. Pigot, and M. Pook, 2007: The years of El Niño, La Niña and interactions with the tropical Indian Ocean. J. Climate, 20, 2872-2880, https://doi.org/10.1175/JCLI4152.1.

Moore, A. M., and R. Kleeman, 1999: The nonnormal nature of El Niño and intraseasonal variability. J. Climate, 12, 2965-2982, https://doi.org/10.1175/1520-0442(1999)012<2965:TNNOEN>2. $0 . \mathrm{CO} ; 2$.

Morioka, Y., T. Tozuka, and T. Yamagata, 2010: Climate variability in the southern Indian Ocean as revealed by selforganizing maps. Climate Dyn., 35, 1059-1072, https://doi.org/ 10.1007/s00382-010-0843-x.

,$- \ldots$, and — 2013: How is the Indian Ocean subtropical dipole excited? Climate Dyn., 41, 1955-1968, https://doi.org/ 10.1007/s00382-012-1584-9.

Moron, V., R. Vautard, and M. Ghil, 1998: Trends, interdecadal and interannual oscillations in global sea-surface temperatures. Climate Dyn., 14, 545-569, https://doi.org/10.1007/ s003820050241. 
Mukhin, D., A. Gavrilov, A. Feigin, E. Loskutov, and J. Kurths, 2015: Principal nonlinear dynamical modes of climate variability. Sci. Rep., 5, 15510, https://doi.org/10.1038/srep15510.

Newman, M., 2007: Interannual to decadal predictability of tropical and North Pacific sea surface temperatures. J. Climate, 20, 2333-2356, https://doi.org/10.1175/JCLI4165.1.

— , and P. D. Sardeshmukh, 2008: Tropical and stratospheric influences on extratropical short-term climate variability. J. Climate, 21, 4326-4347, https://doi.org/10.1175/2008JCLI2118.1.

- , and — 2017: Are we near the predictability limit of tropical Indo-Pacific sea surface temperatures? Geophys. Res. Lett., 44, 8520-8529, https://doi.org/10.1002/2017GL074088.

,-- C. R. Winkler, and J. S. Whitaker, 2003: A study of subseasonal predictability. Mon. Wea. Rev., 131, 1715-1732, https://doi.org/10.1175//2558.1.

—, M. A. Alexander, and J. D. Scott, 2011: An empirical model of tropical ocean dynamics. Climate Dyn., 37, 1823-1841, https://doi.org/10.1007/s00382-011-1034-0.

— , and Coauthors, 2016: The Pacific decadal oscillation, revisited. J. Climate, 29, 4399-4427, https://doi.org/10.1175/ JCLI-D-15-0508.1.

Nieves, V., J. K. Willis, and W. C. Patzert, 2015: Recent hiatus caused by decadal shift in Indo-Pacific heating. Science, 349, 532-535, https://doi.org/10.1126/science.aaa4521.

Penland, C., 1989: Random forcing and forecasting using principal oscillation pattern analysis. Mon. Wea. Rev., 117, 2165-2185, https://doi.org/10.1175/1520-0493(1989)117<2165:RFAFUP $>2$. $0 . \mathrm{CO} ; 2$.

— 1996: A stochastic model of IndoPacific sea surface temperature anomalies. Physica D, 98, 534-558, https://doi.org/ 10.1016/0167-2789(96)00124-8.

_ , and L. Matrosova, 1994: A balance condition for stochastic numerical models with application to the El Niño-Southern Oscillation. J. Climate, 7, 1352-1372, https://doi.org/10.1175/ 1520-0442(1994)007<1352:ABCFSN >2.0.CO;2.

_ , and P. D. Sardeshmukh, 1995: The optimal growth of tropical sea surface temperature anomalies. J. Climate, 8, 1999-2024, https://doi.org/10.1175/1520-0442(1995)008<1999:TOGOTS >2. $0 . \mathrm{CO} ; 2$.

Poli, P., and Coauthors, 2016: ERA-20C: An atmospheric reanalysis of the twentieth century. J. Climate, 29, 4083-4097, https://doi.org/10.1175/JCLI-D-15-0556.1.

Power, S., T. Casey, C. Folland, A. Colman, and V. Mehta, 1999: Inter-decadal modulation of the impact of ENSO on Australia. Climate Dyn., 15, 319-324, https://doi.org/10.1007/ s003820050284.

Rayner, N. A., D. E. Parker, E. B. Horton, C. K. Folland, L. V. Alexander, D. P. Rowell, E. C. Kent, and A. Kaplan, 2003: Global analyses of sea surface temperature, sea ice, and night marine air temperature since the late nineteenth century. J. Geophys. Res., 108, 4407, https://doi.org/ 10.1029/2002JD002670.

Reason, C. J. C., 2002: Sensitivity of the southern African circulation to dipole sea-surface temperature patterns in the south Indian Ocean. Int. J. Climatol., 22, 377-393, https://doi.org/ 10.1002/joc.744.

Saji, N. H., and T. Yamagata, 2003: Possible impacts of Indian Ocean Dipole mode events on global climate. Climate Res., $\mathbf{2 5}$, 151-169, https://doi.org/10.3354/cr025151.

, B. N. Goswami, P. N. Vinayachandran, and T. Yamagata, 1999: A dipole mode in the tropical Indian Ocean. Nature, 401, 360-363, https://doi.org/10.1038/43854.
— S. P. Xie, and T. Yamagata, 2006: Tropical Indian Ocean variability in the IPCC twentieth-century climate simulations. J. Climate, 19, 4397-4417, https://doi.org/10.1175/JCLI3847.1.

Santoso, A., M. H. England, and W. Cai, 2012: Impact of IndoPacific feedback interactions on ENSO dynamics diagnosed using ensemble climate simulations. J. Climate, 25, 7743-7763, https://doi.org/10.1175/JCLI-D-11-00287.1.

Schott, F. A., S. Xie, and J. P. McCreary, 2009: Indian Ocean circulation and climate variability. Rev. Geophys., 47, RG1002, https://doi.org/10.1029/2007RG000245.

Schwarzkopf, F. U., and C. W. Böning, 2011: Contribution of Pacific wind stress to multi-decadal variations in upper-ocean heat content and sea level in the tropical south Indian Ocean. Geophys. Res. Lett., 38, L12602, https://doi.org/10.1029/ 2011GL047651.

Shin, S.-I., P. D. Sardeshmukh, M. Newman, C. Penland, and M. A. Alexander, 2020: Impact of annual cycle on ENSO variability and predictability. J. Climate, 34, 171-193, https://doi.org/ 10.1175/JCLI-D-20-0402.1.

Smith, T. M., R. W. Reynolds, T. C. Peterson, and J. Lawrimore, 2008: Improvements to NOAA's historical merged landocean surface temperature analysis (1880-2006). J. Climate, 21, 2283-2296, https://doi.org/10.1175/2007JCLI2100.1.

Solomon, A., and M. Newman, 2012: Reconciling disparate twentieth-century Indo-Pacific ocean temperature trends in the instrumental record. Nat. Climate Change, 2, 691-699, https://doi.org/10.1038/nclimate1591.

Song, Q., G. A. Vecchi, and A. J. Rosati, 2007: Indian Ocean variability in the GFDL coupled climate model. J. Climate, 20, 2895-2916, https://doi.org/10.1175/JCLI4159.1.

Sun, S., J. Lan, Y. Fang, Tana, and X. Gao, 2015: A triggering mechanism for the Indian Ocean dipoles independent of ENSO. J. Climate, 28, 5063-5076, https://doi.org/10.1175/ JCLI-D-14-00580.1.

Suzuki, R., S. K. Behera, S. Iizuka, and T. Yamagata, 2004: Indian Ocean subtropical dipole simulated using a coupled general circulation model. J. Geophys. Res., 109, C09001, https:// doi.org/10.1029/2003JC001974.

Tozuka, T., J. J. Luo, S. Masson, and T. Yamagata, 2007: Decadal modulations of the Indian Ocean dipole in the SINTEX-F1 coupled GCM. J. Climate, 20, 2881-2894, https://doi.org/ 10.1175/JCLI4168.1.

Trenary, L. L., and W. Han, 2012: Intraseasonal-to-interannual variability of south Indian Ocean sea level and thermocline: Remote versus local forcing. J. Phys. Oceanogr., 42, 602-627, https://doi.org/10.1175/JPO-D-11-084.1.

_ and thermocline depth variability in the south Indian Ocean. J. Geophys. Res. Oceans, 118, 381-398, https://doi.org/10.1029/ 2012JC008317.

van Sebille, E., J. Sprintall, F. U. Schwarzkopf, A. Sen Gupta, A. Santoso, M. H. England, A. Biastoch, and C. W. Böning, 2014: Pacific-to-Indian Ocean connectivity: Tasman leakage, Indonesian Throughflow, and the role of ENSO. J. Geophys. Res. Oceans, 119, 1365-1382, https://doi.org/ 10.1002/2013JC009525.

Vimont, D. J., M. A. Alexander, and M. Newman, 2014: Optimal growth of central and east Pacific ENSO events. Geophys. Res. Lett., 41, 4027-4034, https://doi.org/10.1002/2014GL059997.

von Storch, H., G. Bürger, R. Schnur, and J.-S. von Storch, 1995: Principal oscillation patterns: A review. J. Climate, 8, 377-400, https://doi.org/10.1175/1520-0442(1995)008<0377:POPAR >2. $0 . \mathrm{CO} ; 2$. 
Webster, P. J., A. M. Moore, J. P. Loschnigg, and R. R. Leben, 1999: Coupled ocean-atmosphere dynamics in the Indian Ocean during 1997-98. Nature, 401, 356-360, https://doi.org/10.1038/43848.

$\mathrm{Wu}, \mathrm{R}$., and B. P. Kirtman, 2004: Understanding the impacts of the Indian Ocean on ENSO variability in a coupled GCM. J. Climate, 17, 4019-4031, https://doi.org/10.1175/15200442(2004)017<4019:UTIOTI >2.0.CO;2.

Xie, S. P., H. Annamalai, F. A. Schott, and J. P. McCreary, 2002: Structure and mechanisms of south Indian Ocean climate variability. J. Climate, 15, 864-878, https://doi.org/10.1175/ 1520-0442(2002)015<0864:SAMOSI >2.0.CO;2.

- , K. Hu, J. Hafner, H. Tokinaga, Y. Du, G. Huang, and T. Sampe, 2009: Indian Ocean capacitor effect on Indo-western Pacific climate during the summer following El Niño. J. Climate, 22, 730-747, https://doi.org/10.1175/2008JCLI2544.1.

Yamagata, T., S. K. Behera, J. J. Luo, S. Masson, M. R. Jury, and S. A. Rao, 2004: Coupled ocean-atmosphere variability in the tropical Indian Ocean. Earth's Climate: The OceanAtmosphere Interaction, Geophys. Monogr., Vol. 147, Amer. Geophys. Union, 189-211, https://doi.org/10.1029/147GM12.

Yang, Y., S. P. Xie, L. Wu, Y. Kosaka, N. C. Lau, and G. A. Vecchi, 2015: Seasonality and predictability of the Indian Ocean dipole mode: ENSO forcing and internal variability. J. Climate, 28, 8021-8036, https://doi.org/10.1175/JCLI-D-15-0078.1.

Yu, J.-Y., 2008: Understanding the El Niño-Southern Oscillation and its interactions with the Indian Ocean and monsoon. Recent Progress in Atmospheric Sciences: Application to the Asia-Pacific Region, K. N. Liou and M. D. Chou, Eds., World Scientific, 3-22, https://doi.org/10.1142/9789812818911_0001.

—_, and K. M. Lau, 2005: Contrasting Indian Ocean SST variability with and without ENSO influence: A coupled atmosphere-ocean GCM study. Meteor. Atmos. Phys., 90, 179-191, https://doi.org/10.1007/s00703-004-0094-7.

Zhang, L., 2016: The roles of external forcing and natural variability in global warming hiatuses. Climate Dyn., 47, 31573169, https://doi.org/10.1007/s00382-016-3018-6.

— , and K. B. Karnauskas, 2017: The role of tropical interbasin SST gradients in forcing Walker circulation trends. J. Climate, 30, 499-508, https://doi.org/10.1175/JCLI-D-16-0349.1.

_- , and W. Han, 2018: Impact of Ningaloo Niño on tropical Pacific and an interbasin coupling mechanism. Geophys.
Res. Lett., 45, 11300-11309, https://doi.org/10.1029/ 2018 GL078579.

-,- Y. Li, and T. Shinoda, 2018a: Mechanisms for generation and development of the Ningaloo Niño. J. Climate, 31, 9239-9259, https://doi.org/10.1175/JCLI-D-18-0175.1.

,,-- and F. Sienz, 2018b: Unraveling causes for the changing behavior of the tropical Indian Ocean in the past few decades. J. Climate, 31, 2377-2388, https://doi.org/10.1175/JCLI-D-170445.1.

- — - K. B. Karnauskas, G. A. Meehl, A. Hu, N. Rosenbloom, and T. Shinoda, 2019a: Indian Ocean warming trend reduces Pacific warming response to anthropogenic greenhouse gases: An interbasin thermostat mechanism. Geophys. Res. Lett., 46, 10 882-10 890, https://doi.org/ 10.1029/2019GL084088.

,,-- Y. Li, and N. S. Lovenduski, 2019b: Variability of sea level and upper-ocean heat content in the Indian Ocean: Effects of subtropical Indian Ocean dipole and ENSO. J. Climate, 32, 7227-7245, https://doi.org/10.1175/JCLI-D-190167.1.

Zhang, X., J. Sheng, and A. Shabbar, 1998: Modes of interannual and interdecadal variability of Pacific SST. J. Climate, 11, 2556-2569, https://doi.org/10.1175/1520-0442(1998)011<2556: MOIAIV $>2.0 . \mathrm{CO} ; 2$.

Zhang, X. L., and W. Han, 2020: Effects of climate modes on interannual variability of upwelling in the tropical Indian Ocean. J. Climate, 33, 1547-1573, https://doi.org/10.1175/JCLI-D-190386.1.

Zhang, Y., M. Feng, Y. Du, H. E. Phillips, N. L. Bindoff, and M. J. McPhaden, 2018: Strengthened Indonesian Throughflow drives decadal warming in the southern Indian Ocean. Geophys. Res. Lett., 45, 6167-6175, https://doi.org/10.1029/ 2018GL078265.

Zheng, X. T., S. P. Xie, G. A. Vecchi, Q. Liu, and J. Hafner, 2010: Indian Ocean dipole response to global warming: Analysis of ocean-atmospheric feedbacks in a coupled model. J. Climate, 23, 1240-1253, https://doi.org/10.1175/2009JCLI3326.1.

Zinke, J., W. C. Dullo, G. A. Heiss, and A. Eisenhauer, 2004: ENSO and Indian Ocean subtropical dipole variability is recorded in a coral record off southwest Madagascar for the period 1659 to 1995. Earth Planet. Sci. Lett., 228, 177-194, https://doi.org/10.1016/j.eps1.2004.09.028. 